Ocean Dynamics

June 2015, Volume 65 Issue 6 Pages 845-857

http://dx.doi.org/10.1007/s10236-015-0837-7

http://archimer.ifremer.fr/doc/00270/38129/

(c) Springer-Verlag Berlin Heidelberg 2015

\title{
Mixed-layer salinity budget in the tropical Indian Ocean: seasonal cycle based only on observations
}

\author{
Da-Allada Casimir Yelognisse ${ }^{1,{ }^{*}}$, Gaillard Fabienne ${ }^{3}$, Kolodziejczyk Nicolas ${ }^{2}$ \\ ${ }^{1}$ CNRS Ifremer IRD UBO, IFREMER, LPO, UMR 6523, Plouzane, France. \\ ${ }^{2}$ Univ Paris 06, Univ Paris 04, LOCEAN Lab, CNRS IRD MNHN, F-75005 Paris, France. \\ *Corresponding author : Casimir Yelognisse Da-Allada, email address : daallada@yahoo.fr
}

\begin{abstract}
:
The mixed-layer salinity (MLS) budget in the tropical Indian Ocean is estimated from a combination of satellite products and in situ observations over the 2004-2012 period, to investigate the mechanisms controlling the seasonal MLS variability. In contrast with previous studies in the tropical Indian Ocean, our results reveal that the coverage, resolution, and quality of available observations are now sufficient to approach a closed monthly climatology seasonal salt budget. In the South-central Arabian Sea and South-western Tropical Indian Ocean (SCAS and STIO, respectively), where seasonal variability of the MLS is pronounced, the monthly MLS tendency terms are well captured by the diagnostic. In the SCAS region, in agreement with previous results, the seasonal cycle of the MLS is mainly due to meridional advection driven by the monsoon winds. In the STIO, contrasting previous results indicating the control of the meridional advection over the seasonal MLS budget, our results reveal the leading role of the freshwater flux due to precipitation.
\end{abstract}

Keywords: Tropical Indian Ocean, Observations, Seasonal cycle, Mixed-layer salinity, Mixed-layer budget 


\section{Introduction}

The Indian Ocean is characterised by seasonally reversing monsoon winds north of $10^{\circ} \mathrm{S}$, which force a seasonal turnover of the upper ocean circulation (Shankar et al. 2002, Schott et al. 2009). From May to September, the southwesterly winds force the surface Summer Monsoon Current (SMC) to flow eastward. In contrast, from November to February, the Winter Monsoon Current (WMC) flows westward north of the equator, in response to the northeasterly winds. Both monsoon currents (SMC and WMC) force the exchange of surface waters between the highly contrasted Arabian Sea (to the west) and Bay of Bengal (to the east). Specifically, the WMC carries fresher Bay of Bengal waters into the Arabian Sea, while the SMC brings saltier Arabian Sea water into the Bay of Bengal (Jensen, 2003).

Salt transported by the currents plays a key role in the tropical climate through its effects on upper ocean stratification. Salinity can indeed limit the thickness of the mixed-layer by creating a barrier layer and therefore constraint the ocean-atmosphere interactions (Lukas and Lindstom, 1991, Sprintall and Tomczak 1992, Pailler et al. 1999). The barrier layer has been shown to be important in the dynamics of the Indian Ocean using a regional coupled model (Masson et al. 2005, Seo et al. 2009), an ocean general circulation model (Durand et al. 2007) but also based on observations (Vinayachandran et al. 2002, Rao and Sivakumar, 2003, Mignot et al. 2007). Furthermore salinity is thought to be a possible indicator of changes in the hydrological cycle (Webster, 1994; Yu, 2011, Terray et al., 2012, Da-Allada et al, 2014a).

Previous studies have investigated the observed seasonal variability of sea surface salinity (SSS) in the tropical Indian Ocean with the available data sets. Based on measurements of SSS collected from ships of opportunity along six shipping tracks, large seasonal SSS variability is found over the western Indian Ocean while the eastern part of the basin shows little variability, except for regions of intense local rainfall and river runoff like the Bay of 
73 Bengal (Donguy and Meyers, 1996). The analysis of climatological salinity data (Rao and 74 Sivakumar, 2003) extended the previous study and revealed that the northern Indian Ocean exhibits a larger SSS variability than the southern Indian Ocean.

The north Indian Ocean mixed-layer salinity (MLS) budget based on the same SSS data together with other measurements (atmospheric flux and currents) quantifies the relative contribution of the atmospheric freshwater flux and SSS horizontal advection (Rao and Sivakumar, 2003). According to these authors the horizontal advection and freshwater flux are both important to explain the SSS variability during the summer monsoon, while horizontal advection clearly dominates the salt budget during the winter monsoon.

However, this study was limited by data availability and did not investigate all the processes, such as vertical advection, entrainment at the mixed-layer base and diffusion terms. These terms may significantly contribute to the seasonal SSS balance, as was shown in other basins of the Pacific and the Atlantic oceans (Vialard and Delecluse, 1998; Vialard et al., 2002; Qu et al., 2011; Vinogradova and Ponte, 2013; Hasson et al., 2013; Kolodziejczyk and Gaillard, 2013; Da-Allada et al., 2013; Da-Allada et al, 2014b).

To better quantify the contribution of each term of the salinity balance in the Indian Ocean, a coupled ocean-atmosphere model with no relaxation to SSS observations was used (Vinayachandran and Nanjundiah, 2009). This study showed that the freshwater input to the ocean and its redistribution by ocean circulation are the crucial processes to the salt budget. These authors also showed like in the observations that the SSS tendency is mainly due to horizontal advection during winter, whereas both advection and freshwater fluxes are necessary to explain the SSS tendency during the summer. However, the model SSS was found to be underestimated (1-1.5 pss bias) in comparison with the observed climatology. 
This was attributed to the poor representation of orography in the atmospheric component of the coupled model.

Meridional advection was found to be the mechanism which controls the seasonal cycle of the MLS in the southwestern tropical Indian Ocean by Halkides and Lee (2011). They used an Ocean General Circulation Model (OGCM) with a relaxation term toward the observed SSS climatology to compensate for errors in the forcing or in the model physics. In this region characterised by a pronounced thermocline ridge, in the heat budget based on observations, Foltz et al. (2010), found that the seasonal cycle of Sea Surface Temperature (SST) is driven by a combination of the net surface heat flux, horizontal heat advection and vertical turbulent mixing. Note that a similar result was found in the heat budget using an OGCM in the western Arabian Sea by de Boyer-Montégut et al, (2007). In the eastern part of Arabian Sea (with a meridional separation at $65^{\circ} \mathrm{E}$ ), they concluded that the SST seasonal cycle is dominated by surface forcing, while the oceanic processes play a second role. They showed that salinity stratification plays a significant role in maintaining the high winter SST in the eastern part of the Arabian Sea. In the SSS case, as the relaxation term used in Halkides and Lee (2011) also could be sometimes significant in some regions, the conclusions about the mechanisms of SSS variability may not be fully closed.

The recent development of the Argo array in the Indian Ocean has improved the coverage and resolution of available temperature and salinity profiles. In the present study, we use a combination of in situ and satellite products to provide more insight into the main mechanisms that modulate the MLS seasonal evolution in the tropical Indian Ocean. In particular, we reveal here the role of the freshwater flux due to precipitation which controls the seasonal evolution of the MLS in the southwestern tropical Indian Ocean and was missed by previous studies. 

section2. Section3 presents the results and finally, discussion and conclusion of the new

122 results are presented in section4.

\section{Methodology and Data}

\subsection{Methodology}

Following Da-Allada et al. (2013), the mixed-layer salinity evolution equation (Eq.1) can be written as follows:

$$
\frac{\partial S_{m}}{\partial t}=\underbrace{\frac{(E-P) S_{m}}{h_{m}}}_{F W F} \underbrace{-\overrightarrow{\mathbf{u}_{\mathrm{m}} \cdot \vec{\nabla} S_{m}}}_{H A D V}-\underbrace{H\left(w_{e}\right) \frac{\left(S_{m}-S_{h_{m}}\right)}{h_{m}}}_{E N T}+\underbrace{K \nabla^{2} S_{m}}_{D I F H}+\varepsilon
$$

where $S_{m}$ is the salinity average in the mixed-layer, $\mathrm{t}$ is the time, $\mathrm{E}$ is evaporation, $\mathrm{P}$ is precipitation, $\mathrm{h}_{\mathrm{m}}$ is the mixed-layer depth (MLD), $\boldsymbol{u}_{\boldsymbol{m}}$ is the horizontal surface velocity vector averaged over the mixed-layer (having $\mathrm{u}$ and $\mathrm{v}$ components defined positive eastward and northward, respectively), $S_{h_{m}}$ is the salinity at the base of the mixed-layer, $w_{e}=w+\frac{\partial h_{m}}{\partial t}$ is the entrainment velocity (at depth $\mathrm{z}^{-=} h_{m}$ ) which corresponds to the difference between the vertical velocity ${ }^{w}$ (positive when upwards and estimated from the horizontal currents through the continuity equation) at the mixed-layer base and the mixed-layer deepening rate, $H\left(w_{e}\right)$ is the Heaviside step function $\left(H\left(w_{e}\right)=w_{e}\right.$ if $w_{e}>0$ and $H\left(w_{e}\right)=0$ if $w_{e}<0$ ) and $\mathrm{K}$ (set to $500 \mathrm{~m}^{2} . \mathrm{s}^{-1}$ as in Yu, 2011 and in Dong et al., 2009) is the horizontal diffusivity. Note that the river runoff is not quantified in this study because the studied areas are far from coastal regions. The lhs term of Eq.1 represents the MLS tendency and the rhs terms represent the surface freshwater flux (FWF), horizontal advection (HADV), vertical physics in the form of entrainment (ENT), horizontal diffusion (DIFH) and the sum of all unresolved physical processes (especially vertical turbulent mixing) and the accumulation of errors from the other 
142 terms calculated ( ${ }^{\varepsilon}$ ), respectively. The horizontal advection is also decomposed into Ekman 143 and geostrophic components. The Ekman velocity is calculated as $u_{e}=\frac{1}{\sigma_{o} f h_{m}}\left(\tau^{y}-\tau^{x}\right)$

144 where $\tau^{x}$ is the zonal wind stress, $\tau^{y}$ is the meridional wind stress, $\mathrm{f}$ is the Coriolis 145 parameter and $\sigma_{o}$ (set to $1027 \mathrm{~kg} \cdot \mathrm{m}^{-3}$, Li et al., 2013) is the reference density of seawater. 146 The geostrophic velocity is deduced from the difference between total horizontal velocity and 147 Ekman velocity. The ENT term contains subsurface vertical processes occurring at the base of 148 the mixed-layer: vertical advection from below the mixed-layer (related to the effects of 149 thermocline heaving) and entrainment mixing (when the mixed-layer deepens). In addition, 150 the entrainment terms may be sensitive to accuracy of the horizontal currents, salinity gradient 151 at the base of the mixed layer, and the MLD (Kolodziejczyk et al., 2013; Da-Allada et al., 152 2013). The vertical turbulent mixing (associated with small scale turbulent Reynolds terms) 153 can not be resolved by the data set because it results from vertical spatio-temporal variability 154 (Reynolds terms) occurring at smaller scale than the vertical resolution of the data sampling. We neglected this term as we are not able to evaluate and its contribution thus appears in the residual and contributes to the MLS budget imbalance. The lhs of Eq.1 (MLS tendency) can

157 be obtained either from observations or computed as the sum of the rhs (diagnostic). In this 158 study, the lhs term of Eq.1 is referred to as the MLS tendency and the sum of forcing terms in 159 the rhs of Eq.1 as the diagnosed MLS tendency. In order to compute the contribution of the different terms of the mixed-layer salinity 161 balance to the salinity tendency, the following variables are needed: mixed-layer and 162 subsurface salinity, mixed-layer depth, freshwater flux, wind stress and the surface currents. 163 The vertical velocity at the mixed-layer base is estimated from horizontal currents using the 164 continuity equation. 
The mixed-layer and subsurface salinity are provided by the In Situ Data Analysis System (ISAS, Gaillard et al. 2009) monthly gridded fields of temperature and salinity optimally interpolated mainly from Argo profiles and a few other CTD observations including marine mammals and moorings (Gaillard et al. 2009). The ISAS product is provided with the monthly errors in salinity and temperature associated with each grid point. This error is given as a percentage of a priori variance at each point which depends mainly on the sampling. The annual mean error on MLS (Figure 1a) is less than 70\% in the open ocean and could reach $100 \%$ near shore due to poor data coverage in these areas. This study focuses on two regions where error on MLS is less than 70\% to compute the salt budget: the South-central Arabian Sea (SCAS, $1.5^{\circ}-13^{\circ} \mathrm{N}, 56^{\circ}-70^{\circ} \mathrm{E}$ ) and the South-western tropical Indian Ocean (STIO, $5^{\circ}-$ $\left.12^{\circ} \mathrm{S}, 50^{\circ}-75^{\circ} \mathrm{E}\right)$. The number of Argo profiles on each box for each month between 2004 and 2012 is shown in the Figure 2. In the two boxes, we have about 40 profiles per month an average with a maximum of 120 profiles in mid-2004 in the SCAS and about 90 profiles in early 2007 in the STIO. The choice of these two regions is not only based on the MLS error but also on the MLS variability (see below). The ISAS fields are computed on a grid with a $0.5^{\circ} \times 0.5^{\circ}$ horizontal resolution and 152 depth levels. The vertical spacing is $5 \mathrm{~m}$ in the first $100 \mathrm{~m}$ and then $10 \mathrm{~m}$ down to $200 \mathrm{~m}$. We used the ISAS13 monthly climatology which is an average over the period 2004-2012.

The MLD is derived from the monthly temperature and salinity fields of this climatology 185 using density criteria which have been used by several authors (e.g. de Boyer Montégut et al, 186 2004; Dong et al, 2009; Yu, 2011). Based on the sensitivity tests discussed in the Appendix, we find that the criterion of a $0.125 \mathrm{~kg} \cdot \mathrm{m}^{-3}$ density change relative to the near surface value (selected at $10 \mathrm{~m}$ because of better data sampling than 0 or $5 \mathrm{~m}$ ) is more appropriated to close 
the MLS budget in our studied area, thus it is used for the reference experiment. The MLD obtained (with ISAS13) is compared with the product of de Boyer Montégut et al (2004) in

191 the result part. The subsurface salinity $S_{h_{m}}$ is chosen as the salinity 15 m below the MLD (as in Ren et al, 2011). This choice is motivated by the sensitivity tests described in the appendix. We find that, the MLS budget is sensitive to the choice of the salinity at the mixed-layer base and to the density criteria used to compute the MLD. The different results obtained with the 195 sensitivity tests are summarized in the Taylor diagrams (Taylor, 2001) which provides 196 statistical parameters (standard deviation, root mean square difference (RMSD) and correlation coefficient, Figure A in Appendix).

198 The net freshwater fluxes are obtained from atmospheric reanalysis and satellite data sets. 199 Three datasets available over the 2004-2012 period are considered. For the reference 200 experiment, evaporation is from the Objectively Analysed air-sea Fluxes (OAFlux-E) data set 201 (Yu et al. 2008) which is a monthly value at $1^{\circ}$ resolution; and monthly precipitation fields are from the Global Precipitation Climatology Project (GPCP-P) given with a resolution of $2.5^{\circ}$ grid (Alder et al. 2003). The OAFlux-E and GPCP-P were linearly interpolated on the MLS grid for a consistent analysis across all fields. The two others products tested in this 205 study are described in the appendix.

206 The advection is estimated with two different products. We used the OSCAR (Ocean 207 Surface Current Analysis Realtime) surface current of Bonjean and Lagerloef (2002) obtained 208 from satellite sea level, wind stress, and SST, using a diagnostic model. The OSCAR product 209 available on a $1 / 3^{\circ} \times 1 / 3^{\circ} \times 5$ day is selected in this study using the sensitivity tests shown in 210 Appendix (Figure A). The second other current product tested is described in the Appendix. 211 All the tests performed in this study allow us to estimate the error bars on diagnosed MLS 
tendency term. The wind stress obtained from ERA interim reanalysis is used to estimate the Ekman velocity.

All the data used in this study are taken from the same 2004-2012 period and linearly interpolated on the MLS grid for consistent analysis. Based on sensitivity tests, we used the OSCAR current, OAFLUX-GPCP freshwater flux, salinity at $15 \mathrm{~m}$ below the mixed-layer, the MLD based on density criteria $0.125 \mathrm{~kg} \cdot \mathrm{m}^{-3}$ for the reference experiment with ISAS MLS to estimate the seasonal salt budget.

\section{Results}

The large spatial variations of the hydrological forcing in the various areas of the tropical Indian Ocean induce very distinct patterns in the annual mean of MLS as shown in Figure $1 \mathrm{~b}-\mathrm{c}$. Between $10^{\circ} \mathrm{N}$ and $10^{\circ} \mathrm{S}$, regions of low MLS (around 34.5 pss) are observed under the Inter-Tropical Convergence Zone (ITCZ) region. In the northern Arabian Sea (north of $10^{\circ} \mathrm{N}$ ) high value of MLS are observed (larger than 36 pss) as a result of strong evaporation. In contrast, in the northwestern coastal regions of the Bay of Bengal, the MLS is minimum due to strong river discharges into the ocean (Ganges, Brahmaputra, Mahanadi and Godavari Rivers). South of $10^{\circ} \mathrm{S}$, low values of MLS are also observed although evaporation dominates in this region which indicates that ocean dynamics might be of importance. In particular, the westward-flowing South Equatorial Current (SEC) located south of $10^{\circ} \mathrm{S}$

230 (Figure 3a-b) may explain these low salinities. Note also that the eastward flowing SMC 231 represented by July around $2^{\circ}-6^{\circ} \mathrm{N}$ and westward-flowing WMC represented by January 232 located around $3^{\circ}-6^{\circ} \mathrm{N}$ are visible in Figure 3a-b.

MLS shows larger variability north of the equator than in the southern part (Figure 
saline and freshwaters (Donguy and Meyers, 1996, Rao and Sivakumar, 2003). The largest

MLS are observed near the eastern coast of India and Bangladesh.

As explained in the sensitivity test presented in the appendix, the MLD is an important variable for the salinity balance. In boreal winter (represented by January), the MLD used for the computation is generally shallower than $60 \mathrm{~m}$, except north of $10^{\circ} \mathrm{N}$ where MLD is larger (Figure 3c). In boreal summer (represented by July), the largest MLD ( $>70 \mathrm{~m}$ ) are mainly located south of $10^{\circ} \mathrm{S}$ and around $10^{\circ} \mathrm{N}$ (Figure 3d). It should be noted that this MLD is on average greater (13 $\mathrm{m}$ in winter and $30 \mathrm{~m}$ in summer) than the widely used MLD product of de Boyer-Montégut et al. (2004) which is based on a 0.03 kg.m-3 density criteria (not shown). The patterns of the differences between these two MLD have large space variability and can reach $20 \mathrm{~m}$ in winter and $40 \mathrm{~m}$ in summer. The differences found here are comparable to those observed in the tropical Pacific Ocean by Hasson et al (2013) when they compared their MLD based on a $0.01 \mathrm{~kg}$. m-3 density criterion with that of de Boyer-Montégut et al. (2004). Since a better closure of the salt budget is obtained in regions of the Indian ocean that we are studying with the reference MLD (Figure A), this criterion was preferred to the one defined by de Boyer Montégut et al. (2004).

The two specific open ocean regions selected in this study (SCAS and STIO) are characterised by large seasonal MLS variability. Note that in the heat budget, the Arabian Sea was separated into two parts with a meridional separation at $65^{\circ} \mathrm{E}$ to illustrate the different mechanisms which control the SST balance in the eastern and western parts of Arabian Sea (de Boyer-Montégut et al, 2007). In this study no significant change has been noted in MLS budget by changing the SCAS box eastward limit from $65^{\circ} \mathrm{E}$ to $70^{\circ} \mathrm{E}$. The STIO box was designed to follow Halkides and Lee (2011) to perform strict comparisons with our results. Extending eastward the STIO box toward the eastern tip of the SSS maximum does not 
significantly change the results (not shown). MLS exhibits a well marked annual cycle in the two focused regions (Figure 4). The STIO MLS is maximum (minimum) in September (March), one month before the maximum (minimum) in the SCAS. STIO MLS shows slightly lower amplitude (0.7 pss) than the SCAS MLS region (0.8 pss).

In the SCAS region, the diagnosed MLS tendency from the sum of the rhs terms of the salinity balance equation (Eq. 1) matches the observed one within error bars ( $\mathrm{r}=0.97$ at the 265 99\% significance level)(Figure 5a). These two estimates reach their maximum in June and their minimum in January. The dominant terms of the salinity balance are the horizontal advection terms, mainly driven by the meridional component (Figure 5b-c). This term shows a strong seasonal cycle compared to the other terms in the salinity balance. This term is negative from November to April with the maximum freshening effect in January caused by the maximum northward velocity in presence of positive meridional MLS gradient (Figure 6b). This is explained as follows. During the winter monsoon, the northeasterly trade winds are reinforced, driving strong northward Ekman transport over the SCAS (Beal et al, 2013). 273 So, the relatively freshwater in this region is transported northward into the SCAS and results 274 in a strong decrease observed in meridional Ekman advection (Figure 5c). During the rest of 275 the year (May to October), meridional advection remains positive due to southward advection of haline surface water from the Arabian Sea. During the summer monsoon, the southwestward trade winds strengthen and lead to a strong southward Ekman transport (Beal et al, 2013) which carries the Arabian saline water from the north into the SCAS (Figure 5c).

279 The June peak of meridional advection is responsible for the annual peak in observed and diagnosed MLS tendencies. Zonal advection shows a semi-annual cycle but has weaker amplitude than the meridional advection annual cycle. It is negative during the winter monsoon (when it reinforces the meridional component) because of the westward WMC 
which carries fresher Bay of Bengal water into the Arabian Sea (Figure 6a) and during the summer monsoon due to the eastward SMC in presence of positive zonal MLS gradient (then it moderates the meridional component). The maximum freshening effect in this term appears in February and it remains positive during the rest of the year. The seasonality of horizontal advection is thus mainly associated to the monsoon winds in this region ( $\mathrm{Yu}, 2011$; Beal et al, 2013). The seasonal cycle of atmospheric freshwater flux is small except from January to April. During this period, it is positive due to an excess of evaporation (Figure 6c) and reduces to $0.1 \mathrm{pss} / \mathrm{month}$ the freshening effect of the horizontal advection. The entrainment term is also small and positive throughout the year and brings salty water from the interior into the mixed-layer. It shows the strongest contribution (0.1 pss/month) in May due to the maximum entrainment velocity (Figure 6d) and to the increase in vertical salinity gradient as a result of precipitation observed in May in this region (Figure 6c). The thermocline shoaling appears to be too weak to enhance the vertical gradient and thus upward advection of salt (Figure 7a), while the deepening of the mixed-layer could contribute slightly to the entrainment term during the April-July period (Figure 7a). The small difference between diagnosed and observed MLS could results from residual vertical mixing which are not properly resolved. Horizontal diffusion is negligible in this region. the observed ( $r=0.97$ at the $99 \%$ significance level). However, the two estimates do not 302 exactly match within error bars (Figure 8a), except for the July-October period. In this region 303 the closure of the MLS budget appears to be very sensitive to ocean surface currents (Figure 304 A). Using drifter currents instead of OSCAR, the observed and diagnosed MLS tendencies matches within error bars (figure not shown). The main difference observed in the salt budget when using drifter currents manifests by a larger contribution of the entrainment term that 
reaches $0.07 \mathrm{pss} / \mathrm{month}$ instead of $0.04 \mathrm{pss} / \mathrm{month}$ with OSCAR. The diagnosed MLS tendency reaches its maximum in July, one month after the observed estimate. These two estimates are negative from September to March and positive during the rest of the year (April to August). In contrast with the SCAS region, during October to April, the freshwater flux and entrainment terms play an important role in MLS balance as zonal and meridional advection tend to compensate each other except in winter (Figure 8b-c). During this period, the freshwater flux is dominated by precipitation (Figure 9c) and contributes significantly to decrease the MLS and to increase the salinity vertical gradient at the mixed-layer base. The entrainment term, which contribute positively to MLS tendency, may results from the

316 difference between the MLS and subsurface salinity because the entrainment velocity is weak 317 (Figure 9d). On the other hand, the thermocline vertical motion is rather weak to enhance the 318 vertical gradient during this period (Figure $7 \mathrm{~b}$ ). Thus, the salinity entrainment from 319 subsurface may respond to the heavy rainfall during the boreal winter, then slightly persist 320 until May-June. Interestingly, the budget remains unclosed only during the period of 321 significant entrainment term contribution (October-June) and of shallow MLD (Fig. 7). We 322 know that the vertical mixing is not captured by the entrainment term. So that this residual 323 includes at least the vertical mixing. During May to September, the MLS tendency is mainly 324 driven by the meridional advection. Like in the SCAS, the southward advection of haline 325 water from the north increases the MLS in the STIO (Figure 9b). This term is positive in this 326 period with maximum increasing effect in June due to the maximum southward current in 327 presence of positive meridional MLS gradient. Indeed, salinity increases northward and the 328 meridional current is strong and southward in summer due to the monsoon forcing of Ekman 329 transport (Figure 8c). The zonal advection is slightly negative in this period due to westward 330 current and negative zonal MLS gradient (Figure 9a) and this term contributes to reduce the 
meridional advection. Freshwater flux is dominated by evaporation (Figure 9c) during May to

September and increases the MLS tendency. Note that although there is clearly the deepening of the mixed-layer during May-September, its contribution to the entrainment term is weak except in May-June. As for the SCAS, our estimation of the horizontal diffusion is negligible.

\section{Discussion and Conclusion}

In this paper, we investigated the mechanisms that contribute to the seasonal cycle of the mixed-layer salinity budget in the tropical Indian Ocean using a combination of satellite products and in situ observations for the period 2004-2012. We focused this study on two particular regions characterized by important MLS variability : the South-central Arabian Sea (SCAS; $1.5^{\circ}-13^{\circ} \mathrm{N}, 56^{\circ}-70^{\circ} \mathrm{E}$ ) and Southwestern tropical Indian Ocean (STIO; $5^{\circ}-12^{\circ} \mathrm{S}, 50^{\circ}-$ $75^{\circ} \mathrm{E}$ ). The seasonal cycle of the directly observed MLS tendency is well reproduced by the diagnosed MLS tendency in the two regions. It is especially the case in the SCAS where the processes which are dominating the MLS budget are better captured with the coverage, resolution and quality of the available observations, as previously shown in the tropical Atlantic (Da-Allada et al, 2013).

In the SCAS region, in agreement with previous studies based on observations and models (e.g. Rao and Sivakumar, 2003, Vinayachandran and Nanjundiah, 2009), our results show that horizontal advection driven by the seasonally reversing monsoon winds plays a crucial role in the MLS seasonal cycle. We find that the contribution of this term is mainly explained by the meridional advection associated with the Ekman transport which is northward during the northeast monsoon and southward during the southwest monsoon. Atmospheric freshwater flux dominated by evaporation (except in May and in October) acts to increase the MLS. The contribution of this term in the salt budget is small in the second half of the year. The vertical entrainment term due to the increase in vertical salinity gradient 
as a result of freshwater flux and the deepening of the mixed-layer contributes to slightly increase MLS mainly in boreal winter and spring. During the rest of the year (from July to December), the contribution of the entrainment term is very weak. Horizontal diffusion is negligible in this region.

In this study, we find that the entrainment term which was neglected by Rao and Sivakumar (2003), although small, significantly contributes to close the salt budget in the SCAS. This term shows the greatest contribution ( $0.1 \mathrm{pss} / \mathrm{month})$ in the salinity balance in May. Contrary to Vinayachandran and Nanjundiah, 2009 who found a significant negative contribution of freshwater flux in the salinity balance in November in the SCAS region (see their Figure6), we find here, on the basis of observations, that this term is nearly equal to zero at that time of the year. This likely explains why these authors found a lower SSS in the model than in observations (see their Figure 1). of the southeastern Arabian Sea $\left(6^{\circ}-15^{\circ} \mathrm{N}, 68^{\circ}-77^{\circ} \mathrm{E}\right.$; e.g, Masson et al., 2005; Durand et al, 2004). In the SCAS box, we observed that, the vertical salinity gradient across the mixedlayer base is relatively weak and leads only to a small contribution in the entrainment term. Indeed, the chosen SCAS does not include the barrier layer located more eastward in the eastern tropical Indian Ocean. In the STIO region, from October to April, the freshwater flux is mainly due to 374 precipitation and dominates the MLS budget, although the vertical entrainment term linked to 375 the increase in salinity stratification as a result of heavy rainfall and the deepening of the mixed-layer are not negligible. In contrast with the SCAS region, precipitation plays a major 
the SCAS, horizontal advection dominated by meridional advection drives a seasonal evolution of the MLS as freshwater flux and entrainment show a weak contribution.

In the STIO, our results, based on observations, differ from the Halkides and Lee (2011) model study. While they concluded that the seasonal cycle of MLS is dominated only by meridional advection we find in the present study that the freshwater flux is an important contribution in this region, in particular precipitation plays a major role in MLS budget during the boreal winter. It should be noted that the freshwater flux used in our study differs from the one they used. Their model was forced by the freshwater flux derived from the NCEP/NCAR reanalysis product, so, the precipitation minus evaporation could be the source of the difference. Based on sensitivity tests, we find that using the same reference experiment current (OSCAR), salinity at the mixed-layer based (S_h15) and density criteria (h_d0125) with NCEP/NCAR product, the RMSD is twice larger than that obtained with OAFLUXGPCP in the salt budget. Halkides and Lee (2011) also considered a different time period, the SSS seasonal cycle is built on the 1993-2008 period which includes interannual events like the 1997-1998 EL Nino Southern Oscillation (ENSO; e.g. Vialard et al, 2002) and the 1997 Indian Ocean Dipole (IOD; e.g. Masson et al, 2004). The present study is based on the 20042012 period and includes also interannual events like 2009-2010 ENSO (e.g., Kim et al, 2011) and the 2010-2011 IOD (Durand et al, 2013). Note that it is a period with more La Nina than El Niño. Although we only investigated the seasonal cycle, the choice of the period could also be a source of bias of the seasonal cycle, estimating the seasonal budget over a longer time period would reduce this potential bias. Indeed, during strong interannual events (ENSO, IOD), the contribution of each term of the salinity balance could be changed and therefore bias the mean seasonal cycle. As in the SCAS region, the entrainment term neglected by Rao and Sivakumar (2003) appears necessary to close the salt budget and in November, the 
402

403

404

405

406

407

408

409

410

411

412

413

414

415

416

417

418

419

420

421

422

423

424

425

negative contribution of freshwater found by Vinayachandran and Nanjundiah (2009) is twice the size of our estimate.

As in the tropical Pacific (Hasson et al, 2013) and Atlantic (Da-Allada et al, 2013; DaAllada et al, 2014b) Oceans, we find that all terms of the MLS equation have to be taken into account to close the salinity budget. As in the subtropical south-eastern and north-eastern Pacific (Ren and Riser, 2009; Kolodziejczyk and Gaillard, 2013) and in the equatorial Atlantic (Da-Allada et al, 2014b; Berger et al, 2014) which showed that vertical mixing plays a major role in the salinity balance, this term (neglected in this study) also appear to be important in this study and particularly in the STIO region.

The STIO region is characterized by a unique open-ocean upwelling during boreal summer (Xie et al. 2002) and the SST in the STIO exerts an important influence on global climate through its impact on the Indian monsoon and Northern Hemisphere atmospheric circulation (Foltz et al. 2010, Schott et al. 2009). So, understanding the seasonal variability of upper ocean properties in this region is crucial for climate studies. New SSS measurements collected with SMOS (Soil Moisture and Ocean Salinity) are able to detect the signature of IOD (Durand et al. 2013) in this region. The use of the new SMOS SSS dataset or SSS from Aquarius satellite combined with in-situ observations should improve significantly the resolution of the SSS seasonal cycle, especially by resolving the mesoscale variability (Hernandez et al., 2014; Kolodziejczyk et al., 2015) which was not possible with the current resolution of Argo array, and complement the SST seasonal cycle described by several studies (e.g. Foltz et al. 2010). A better understanding of the role of the different terms of the MLS budget as exposed in the present study will permit to evaluate and improve local and global ocean models and lead to increase their predictive skills. 


\section{Appendix: Error Estimates}

In this study, we have performed sensitivity tests before choosing the MLD criterion, the E-P data set, the choice of the depth of the salinity vertical gradient at the base of the mixed-layer and the surface currents products. We tested two density criteria $\left(0.03 \mathrm{~kg} \cdot \mathrm{m}^{-3}\right.$ and $0.125 \mathrm{~kg} . \mathrm{m}^{-3}$ ) of the MLD which are used in several studies (e.g. de Boyer Montégut et al. 2004; Dong et al. 2009; Yu, 2011) and we also used the MLD product of de Boyer Montégut et al (2004) based on density criteria $\left(0.03 \mathrm{~kg} \cdot \mathrm{m}^{-3}\right)$. The reference depth for the vertical density gradient is set to $10 \mathrm{~m}$ because of better data sampling than 0 or $5 \mathrm{~m}$. For the E-P, we tested the product described in the data section with two reanalysis products: the monthly evaporation and precipitation dataset from the ERA-Interim reanalysis (Dee et al. 2011) of the European Centre for Medium-Range Weather Forecasts (ECMWF) available at $0.5^{\circ}$ resolution; and the monthly evaporation and precipitation dataset from the National Center for Environmental Prediction (NCEP) reanalysis1 which are available at $2^{\circ}$ resolution (Kalnay et al, 1996). The surface currents presented in data section are tested with the near-surface velocity average at $15 \mathrm{~m}$ depth deduced from satellite-tracked drifting buoy observations. This product is available on a monthly mean climatology on a $0.5^{\circ} \times 0.5^{\circ}$ grid (Lumpkin and Johnson, 2013). The subsurface salinity at the base of the mixed-layer is tested with three different values: salinity just at the mixed-layer base (S_h0), salinity at $5 \mathrm{~m}$ (S_h5) and at 15 m (S_h15) below the mixed-layer base. Using different combinations of MLD, E-P, salinity at the mixed-layer base and surface current products, we diagnosed 25 MLS tendencies time series for each box. For each of these combinations, observed and diagnosed MLS tendencies are compared and we quantify the similarity between the two estimates by computing the correlation coefficient and root mean square difference (RMSD) which are presented in the 
Taylor diagrams (Figure A). In the SCAS region, the Taylor diagram shows the sensitivity of 451 the region to currents products and we found that the correlation coefficient between observed and diagnosed MLS tendencies is better with OSCAR than drifter currents. We find a small sensitivity when this current (OSCAR) is used with the three different E-P and also the three salinity values at the mixed-layer base. The RMSD between the MLS tendencies (using OSCAR currents) appears more important using different density criteria to compute the MLD than E-P. We noted that, OAFLUX-GPCP and the salinity at $15 \mathrm{~m}$ below the mixedlayer base using OSCAR current and density criteria of $0.125 \mathrm{~kg} \cdot \mathrm{m}^{-3}$ for the MLD give the best correlation (0.97), the smallest RMSD (0.25) and the best (closest to 1) standard deviation ratio (0.95).

460

In the STIO, the values in the Taylor diagram are more dispersed than in the SCAS.

OSCAR and drifter currents give roughly similar results although drifter current slightly improves the correlation between the diagnosed and observed tendencies. This region is more sensitive to E-P, density criteria for MLD and the choice of the depth of salinity gradient at the mixed layer. We selected the OSCAR current with OAFLUX-GPCP, salinity at $15 \mathrm{~m}$ below the mixed-layer and the density criteria $0.125 \mathrm{~kg} \cdot \mathrm{m}^{-3}$ for the reference experiment in the two boxes. To complete sensitivity tests, we replace in the reference experiment, the MLD by 468 the product of de Boyer Montegut et al (2004) which is based on density criteria $0.03 \mathrm{~kg} . \mathrm{m}^{-3}$ 469 (Figure A). In the SCAS, we have obtained RMSD=0.32 instead of 0.24 with the reference 470 MLD, while in the STIO, RMSD $=0.38$ instead of 0.25 with the reference. These results 471 suggest that the reference MLD used in this study is more appropriate to approach the salinity 472 balance than the product of de Boyer Montegut et al (2004). 
All the sensitivity tests are used to estimate the error bar on the diagnosed MLS 474 tendency. Following Da-Allada et al. (2013), standard error is estimated from all the 475 diagnosed tendencies described above, for each month of the seasonal cycle. For the observed MLS tendency, we first estimate monthly error ( $\varepsilon_{S}$ ) in MLS as the 477 standard error of all available observations for each month over the 2004 - 2012 period. Then, 478 errors in MLS ( ${ }^{\varepsilon_{\text {obs }}}$ ) are obtained following Foltz and McPhaden (2008) formula: $\varepsilon_{o b s}=\left(\sqrt{\varepsilon_{S_{t+1}}^{2}+\varepsilon_{S_{t-1}}^{2}}\right) / \Delta t$, with $\Delta t=2$ months. 
C.Y. Da-Allada was supported by an Ifremer post-doctoral grant. The ERA Interim 499 reanalyses products are provided by European Center for Medium-Range Weather Forecasts

500 (http://data-portal.ecmwf.int/data/d/interim_mnth/); the NCEP/NCAR reanalysis products are 501 available at

502 http://www.esrl.noaa.gov/psd/data/gridded/data.ncep.reanalysis.derived.surfaceflux.html, the 503 evaporation OAFlux product is provided by the WHOI OAFlux project 504 (http://oaflux.whoi.edu); the Global Precipitation Climatology Project is available at 505 http://wwW.esrl.noaa.gov/psd/data/gridded/data.gpcp.html; the seasonal climatology of 506 mixed-layer depth is available at

507 http://www.ifremer.fr/cerweb/deboyer/mld/Surface_Mixed_Depth.php and the current data is 508 available at http://www.oscar.noaa.gov for OSCAR currents and for the Global Drifter 509 Program at http://www.aoml.noaa.gov/envids/gld/index.php. 
Adler RF, et al. (2003) The Version 2 Global Precipitation Climatology Project (GPCP) monthly precipitation analysis (1979-present). J. Hydrometeorol.,4, 1147- 1167.

Beal LM, Hormann V, Lumpkin R, Foltz GR (2013) The reponse of the surface circulation of the Arabian Sea to monsoonal forcing. Journal of Physical Oceanography, 43, doi:10.1175/JPO-D-13-033.1.

Berger H, Treguier AM, Talandier C (2014) Dynamical contribution to sea surface salinity variations in the eastern Gulf of Guinea based on numerical modelling. Clim Dyn, doi 10.1007/s00382-014-2195-4.

Bonjean F, Lagerloef GSE (2002) Diagnostic model and analysis of the surface currents in the tropical Pacific Ocean. J. Phys. Oceanogr., 32, 2938-2954.

Da-Allada YC, Alory G, du penhoat Y, Kestenare E, Durand F, Hounkonnou NM (2013) Seasonal mixed-layer salinity balance in the Tropical Atlantic Ocean: Mean sate and seasonal cycle. J. Geophys. Res. Oceans, 118, doi: 10.1029/2012JC008357.

Da-Allada YC, Alory G, du penhoat Y, Jouanno J, Hounkonnou NM, Kestenare E (2014a) Causes for the recent increase in sea surface salinity in the north-eastern Gulf of Guinea. African journal of Marine Science, 36:2, 197-205, doi: 10.2989/1814232X.2014.927398

Da-Allada YC, du Penhoat Y, Jouanno J, Alory G, Hounkonnou (2014b) Modeled mixedlayer salinity balance in the Gulf of Guinea: Seasonal and interannual variability. Ocean Dynamics, doi 10.1007/s10236-014-0775-9

de Boyer Montégut C, Madec G, Fischer AS, Lazar A, Iudicone D (2004) Mixed layer depth over the global ocean: An examination of profile data and a profile-based climatology. Journal of Geophysical Research-Oceans, 109 (C12), 52-71. 
544 de Boyer Montégut C, Vialard J, Shenoi SSC, Shankar D, Durand F, Ethé C, Madec G (2007) 545 Simulated seasonal and interannual variability of mixed layer heat budget in the 546 northern Indian Ocean. J. Clim, 20, 3249-3268.

547 Dee DP, Uppala SM, Simmons AJ, Berrisford P, Poli P, Kobayashi S, Andrae U, Balmaseda 548 MA, Balsamo G, Bauer P, Bechtold P, Beljaars ACM, Van de Berg L, Bidlot J, 549 Bormann N, Delsol C, Dragani R, Fuentes M, Geer AJ, Haimberger L, Healy SB, 550 Hersbach H, H’olm EV, Isaksen L, allberg KP, Kohler M, Matricardi M, McNally AP, 551 Monge-Sanz BM, Morcrette JJ, Park BK, Peubey C, de Rosnay P, Tavolato C, Thépaut 552 553

554 Dong S, Garzoli SL, Baringer M (2009) An assessment of the seasonal mixed layer salinity 555 budget in the Southern Ocean. J. Geophys. Res., 114, C12001, doi: 556 10.1029/2008JC005258

Donguy JR, Meyers G (1996) Seasonal variation of sea-surface salinity and temperature in the tropical Indian Ocean. Deep Sea Res I 43:117-138

559 Durand F, Alory G, Dussin R, Reul N (2013) SMOS reveals the signature of Indian Ocean 560 Dipole events. Ocean Dynamics., 63:1203-1212, doi 10.1007/s10236-013-0660-y

561 Durand F, Shankar D, de boyer Montegut C, Shenoi SSC, Blanke B, Madec G (2007) 562 Modelling the barrier- layer formation in the Southeastern Arabian Sea. J. Clim., 20, 563 2109-2120, doi: 10.1175/JCLI4112.1.

564 Foltz GR, McPhaden MJ (2008) Seasonal mixed layer salinity balance of the tropical North 565 Atlantic Ocean. J. Geophys. Res., 113, C02013, doi: 10.1029/2007JC004178.

566 Foltz GR, Vialard J, Kumar P, McPhaden MJ (2010) Seasonal mixed layer heat balance of the 567 Southwestern Tropical Indian Ocean. J. Clim.,23 doi:10.1175/2009JCLI3268.1. 
Gaillard F, Autret E, Thierry V, Galaup P, Coatanoan C, Loubrieu T (2009) Quality control of large Argo datasets. J. Atmos. Oceanic Technol., 26, 337-351.

Halkides D, Lee T (2011) Mechanisms controlling seasonal mixed layer temperature and salinity in the Southwestern Tropical Indian Ocean. Dynamics of Atmospheres and Oceans., 51, 77-93.

Hasson AEA, Delcroix T, Dussin R (2013) An assessment of the mixed layer salinity budget in the tropical Pacific Oceans. Observations and modelling (1990-2009), Ocean Dynamics, 63(2-3), 179-194, doi:10.1007/s10236-013-0596-2.

Hernandez O, Boutin J, Kolodziejczyk N, Reverdin G, Martin N, Gaillard F, Reul N, Vergely JL (2014) SMOS salinity in the subtropical north Atlantic salinity maximum: Part I: Comparison with Aquarius and in situ salinity. Journal of Geophysical ResearchOceans, doi 10.1002/2013JC009610.

Kalnay E, Kanamitsu M, Kistler R, et al (1996) The NCEP/NCAR 40-year reanalysis project. Bull.Amer.Meteorol. Soc. 77, 437-471.

Kolodziejczyk N, Gaillard F (2013) Variability of the Heat and Salt Budget in the Subtropical Southeastern Pacific Mixed Layer between 2004 and 2010: Spice Injection Mechanisms. Journal of Physical Oceanography, 43, doi:10.1175/JPO-D-13-04.1

Kolodziejczyk N, Hernandez O, Boutin J, Reverdin G (2015) SMOS salinity in the subtropical north Atlantic salinity maximum: Part II: Bi-dimensional horizontal thermohaline variability. In press in Journal of Geophysical Research-Oceans.

Kim W, Yeh SW, Kim JH, Kug JS, Kwon M (2011) The unique 2009-2010 El Nino event: A fast phase transition of warm pool El Nino to La Nina. Geophysical Research Letters, 38, doi:10.1029/2011gl048521. 
Jensen TG (2003) Cross-equatorial pathways of salt and tracers from the northern Indian

Li Y, Wang F, Han W (2013) Interannual sea surface salinity variations observed in the tropical North Pacific Ocean. Geophys. Res. Lett, 40, 2194-2199, doi:10.1002/grl.50429.

Lumpkin R, Johnson GC (2013) Global ocean surface velocities from drifters: Mean, 597 variance, El Nino-Southern Oscillation response, and seasonal cycle. J. Geophys. Res. Oceans, 118, 2992-3006, doi:10.1002/jgrc.20210.

Lukas R, Lindstrom E (1991) The mixed layer of the western equatorial Pacific Ocean. J. Geophys. Res., 96, suppl., 3343-3357.

601

Masson S, et al.(2005) Impact of barrier layer on winter-spring variability of the southeastern

602 Arabian Sea. Geophys. Res. Lett., 32, L07703, doi:10.1029/2004GL021980.

603

Masson S, Boulanger JP, Menkes C, Delecluse P, Yamagata T (2004) Impact of salinity on 604 the 1997 Indian Ocean dipole event in a numerical experiment. J. Geophys. Res., 109, C02002, doi:10.1029/2003JC001807. 607

Mignot J, de Boyer Montegut C, Lazar A, Cravatte S (2007) Control of salinity on the mixed layer depth in the world ocean: 2. Tropical areas. J. Geophys. Res., 112, C10010, doi:

608 10.1029/2006JC003954.

609 Pailler K, Bourlès B, Gouriou Y (1999) The barrier layer in the western tropical Atlantic 610 Ocean. Geophys. Res. Lett., 26, 2069-2072.

611 Qu T, Gao S, Fukumori I (2011) What governs the North Atlantic salinity maximum in a 612 global GCM? Geophys Res Lett 38.doi:10.1029/2011gl046757. 
613 Rao RR, Sivakumar R (2003) Seasonal variability of sea surface salinity and salt budget of 614 the mixed layer of the north Indian Ocean. J. Geophys. Res., 108(C1), 3009, doi: 10.1029/2001JC000907.

Ren L, Riser SC (2009) Seasonal salt budget in the northeast Pacific Ocean. J. Geophys. Res., 114, C12004, doi:10.1029/2009JC005307

618

619

620

621

622

623

624

625

626

627

628

629

630

631

632

633

634

635

636

Ren L, Speer K, Chassignet EP (2011) The mixed layer salinity budget and sea ice in the Southern Ocean. J. Geophys. Res, 116, C08031, doi:10.1029/2010JC006634

Schott FA, Xie SP, McCreary Jr JP (2009) Indian Ocean circulation and climate variability. Rev. Geophys., 47, RG1002, doi:10.1029/2007RG000245.

Seo H, Xie SP, Murtugudde R, Jochum M, Miller AJ (2009) Seasonal effects of Indian Ocean freshwater forcing in a regional coupled model. J. Clim., 22, 6577-6596.

Shankar D, Vinayachandran PN, Unnikrishnan AS (2002) The monsoon currents in the north Indian Ocean, Prog. Oceanogr. 52,63-120, doi:10.1016/S0079-6611(02)00024-1.

Sprintall J, Tomczak M (1992) Evidence of the barrier layer in the surface layer of the tropics. J. Geophys. Res., 97, 7305- 7316.

Terray, L., L. Corre, S. Cravatte, T. Delcroix, G. Reverdin, and A. Ribes (2012) Near-surface salinity as nature's rain gauge to detect human influence on the Tropical water cycle, J. Clim., 25, 958-977, doi:10.1175/JCLI-D-10-05025.1.

Vialard J, Delecluse (1998), An OGCM study for the TOGA decade. Part I:Role of salinity in the physics of the western Pacific fresh pool, Journal of Physical Oceanography, 28(6), 1071-1088, doi:10.1175/1520-0485(1998)028<1071:aosftt>2.0.co;2.

Vialard J, Delecluse P, Menkes C (2002), A modeling study of salinity variability and its effects in the tropical Pacific Ocean during the 1993-1999 period, J. Geophys. Res., 107(C12), doi:8005-10.1029/2000jc000758. 
637

638

639

640

641

642

643

644

645

646

647

648

649

650

651

652

653

654

655

656

657

658

659

660

Vinayachandran PN, Murty VSN, Ramesh Babu V (2002) Observations of barrier layer formation in the Bay of Bengal during summer monsoon. J. Geophys. Res., 107(C12), 8018, doi: 10.1029/2001JC000831.

Vinayachandran PN, Nanjundiah RS (2009) Indian Ocean sea surface salinity variations in a coupled model. Clim Dyn., doi: 10.1007/s00382-008-0511-6.

Vinogradova NT, Ponte RM (2013) Clarifying the link between surface salinity and freshwater fluxes on monthly to interannual time scales. J. Geophys. Res. Oceans, 118, 3190-3201, doi:10.1002/jgrc.20200

Webster PJ (1994) The role of hydrological processes in ocean atmosphere interactions. Rev. Geophys., 32, 427-476.

Xie SP, Annamalai H, McCreary Jr FA (2002) Structure and Mechanisms of South Indian Ocean Climate Variability. J. Clim. 15, 864-878.

Yu L, Jin X, Weller R (2008) Multidecade Global Flux Datasets from the Objectively Analyzed Air-sea Fluxes (OAFlux) Project: Latent and Sensible Heat Fluxes, Ocean Evaporation, and Related Surface Meteorological Variables, 64 pp.

Yu L (2011) A global relationship between the ocean water cycle and near surface salinity. J. Geophys. Res., 116, C10025, doi: 10.1029/2010JC006937. 
662 Figure 1. Annual mean for a) error on mixed-layer salinity (MLS) in percentage of explained variance, b) mixed-layer salinity, c) evaporation (OAFlux-E) minus precipitation (GPCP-P) and d) seasonal standard deviation of MLS.

665 Boxes shown in Figure 1a and d indicate the areas of this study.

666 Annual mean for each product are calculated from monthly averaged values spanning the 667 2004-2012 period. Units are pss for b) and d) ; and mm.day ${ }^{-1}$ for c).

668

Figure 2. Monthly distribution of the available Argo profiles in the SCAS and the STIOregions between 2004 and 2012.

Figure3. Oscar surface currents (1a-b) and ISAS (color) and de boyer Montegut et al., 2004 (contours) product of the mixed-Layer depth (1c-d) for January and July. Unit is m.s ${ }^{-1}$ for (a and b) and $\mathrm{m}$ for (c, d). Contour intervals are $20 \mathrm{~m}$.

Figure4. Seasonal cycle of MLS (in pss) averaged in the SCAS and STIO boxes.

Figure 5. For the SCAS region: a) Observed and diagnosed MLS tendencies with the shaded areas indicating error estimates (see Appendix) for these terms. b) Individual contributions to the salt budget equation for horizontal (zonal + meridional) advection (HADV in blue), entrainment (ENT in dashed blue), freshwater flux (FWF in pink), and horizontal diffusion (DIFH in light blue). c) Decomposition of the horizontal advection into Ekman (dashed green) and geostrophic components (dashed blue).

Figure 6. For the SCAS region: Latitude-time section for the SCAS region. a) Zonal MLS

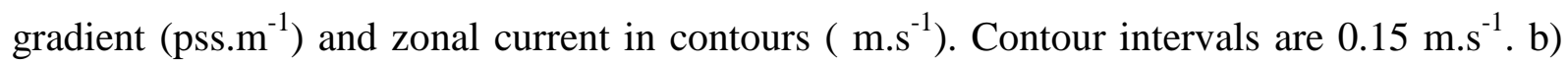
Meridional MLS gradient (pss. $\mathrm{m}^{-1}$ ) and meridional current in contours $\left(\mathrm{m} . \mathrm{s}^{-1}\right)$. Contour intervals are $0.05 \mathrm{~m} . \mathrm{s}^{-1}$. c) Difference between evaporation and precipitation (mm.day $\left.{ }^{-1}\right)$. d) 
685 Salinity gradient near the mixed-layer base (pss) and the positive entrainment velocity in 686 contours $\left(10^{-6} \mathrm{~m} \cdot \mathrm{s}^{-1}\right)$. Contour intervals are $2.5 \mathrm{~m} \cdot \mathrm{s}^{-1}$.

687

688 Figure 7. Vertical profile of the seasonal salinity averaged over the two focal areas a) SCAS 689 and b) STIO. Solid black lines show the mixed-layer depth (MLD) and the $20^{\circ} \mathrm{C}$ isotherm (a 690 proxy for central thermocline depth).

691 Figure 8. Same as Figure 5 except for the STIO region.

692 Figure 9. Same as Figure 6 except for the STIO region. Note that here contour intervals are $6930.08 \mathrm{~m} . \mathrm{s}^{-1}$ for a). Meridional current unit is $10^{-1} \mathrm{~m} . \mathrm{s}^{-1}$ and contour intervals are $0.25 \mathrm{~m} . \mathrm{s}^{-1}$ for 694 b). Contour intervals are $1 \mathrm{~m} \cdot \mathrm{s}^{-1}$ for $\left.\mathrm{d}\right)$.

695 Figure A. Taylor diagram in the SCAS and the STIO regions. Observed and diagnosed MLS 696 tendencies are represented by points on a diagram where the correlation coefficient (R) 697 between the observed and diagnosed time series is given by the azimuthal position, standard 698 deviation of the observed or diagnosed time series is given by the radial distance from the 699 origin, and the centered root mean square difference (RMSD) is given by the distance 700 between the observed point and diagnosed point. REF is the reference experiment. 

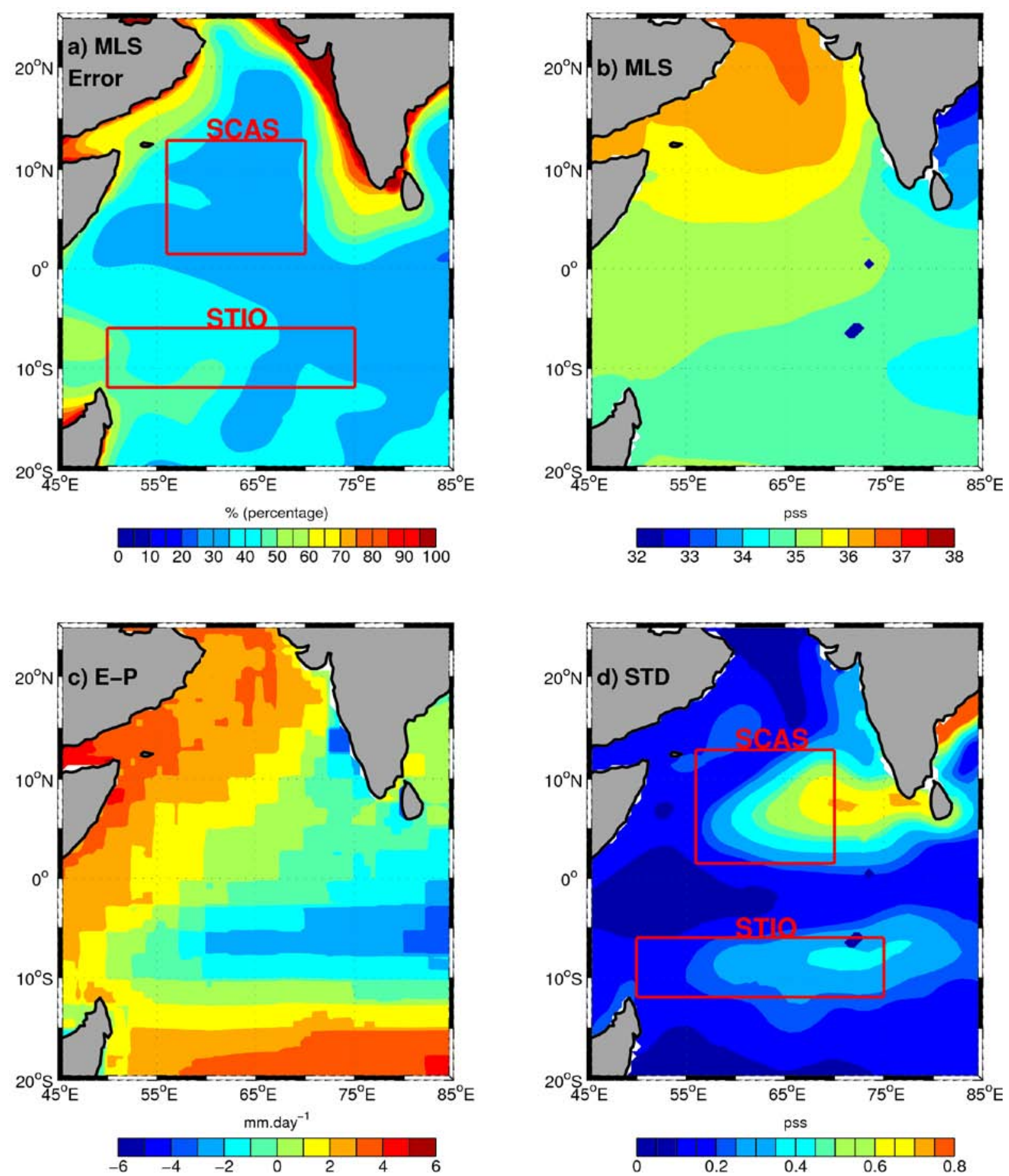

2 Figure 1. Annual mean for a) error on mixed-layer salinity (MLS) in percentage of explained variance, b) mixed-layer salinity, c) evaporation (OAFlux-E) minus precipitation (GPCP-P) and d) seasonal standard deviation of MLS.

5 Boxes shown in Figure 1a and d indicate the areas of this study. 
6 Annual mean for each product are calculated from monthly averaged values spanning the 2004-2012 period. Units are pss for b) and d) ; and mm.day ${ }^{-1}$ for c).

8

9

10

11

12

13

14

15

16

17

18

19

20

21

22

23

24

25

26

27

28

29 


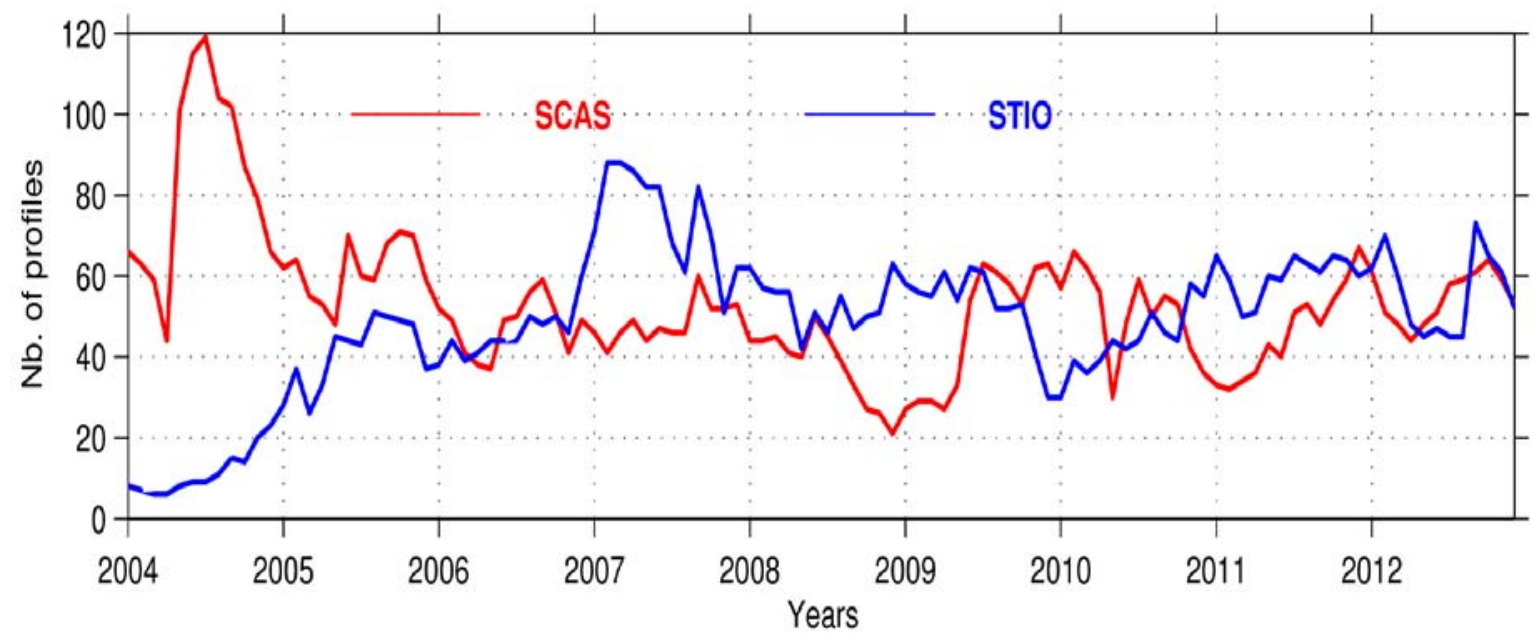

Figure 2. Monthly distribution of the available Argo profiles in the SCAS and the 

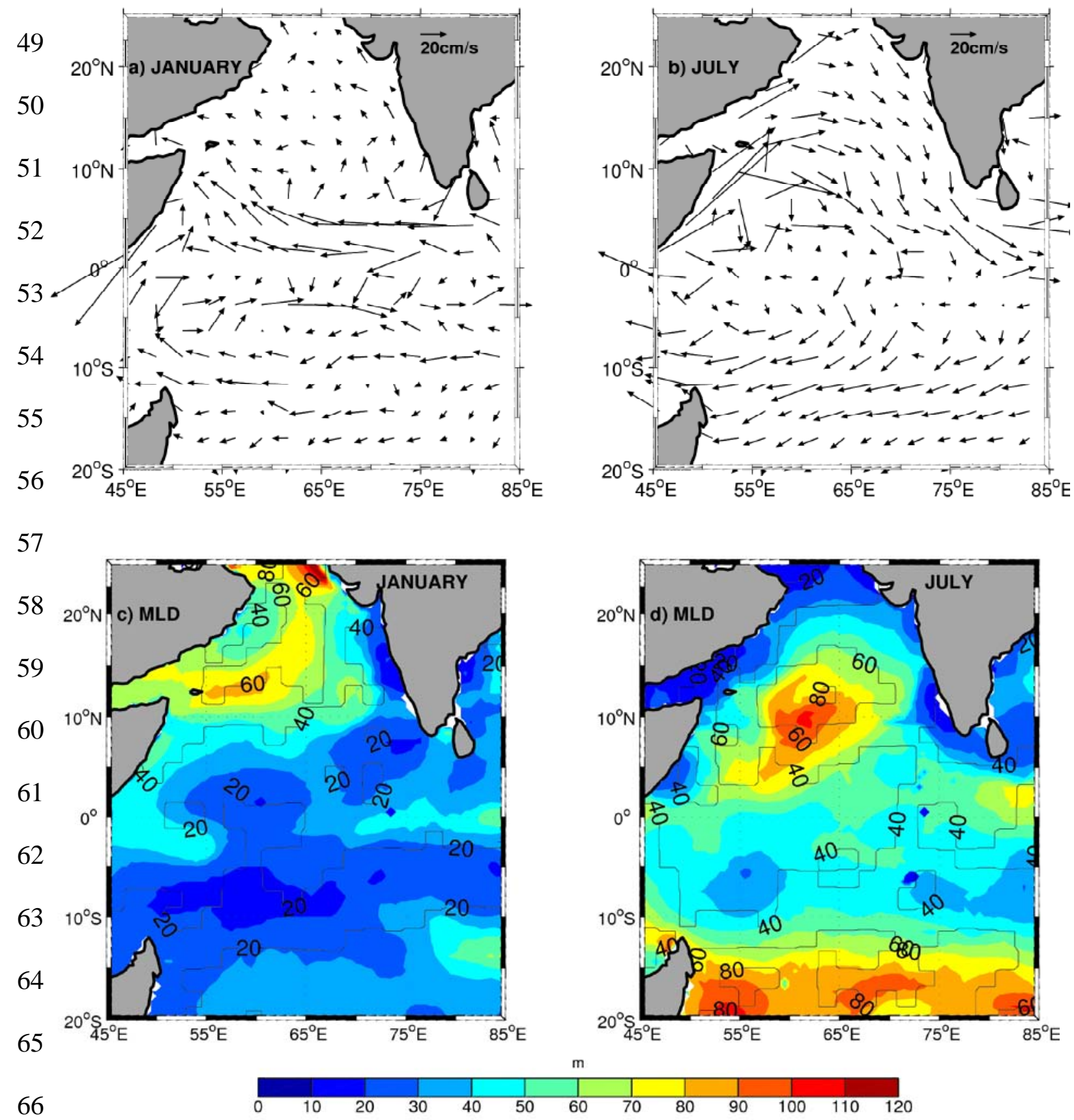

Figure3. Oscar surface currents (a-b) and ISAS (color) and de boyer Montegut et al., 2004 (contours) product of the mixed-layer depth (c-d) for January and July. Unit is $\mathrm{m}_{\mathrm{s}} \mathrm{s}^{-1}$ for (a and b) and $\mathrm{m}$ for (c and d). Contour intervals are $20 \mathrm{~m}$. 
80

81

82

83

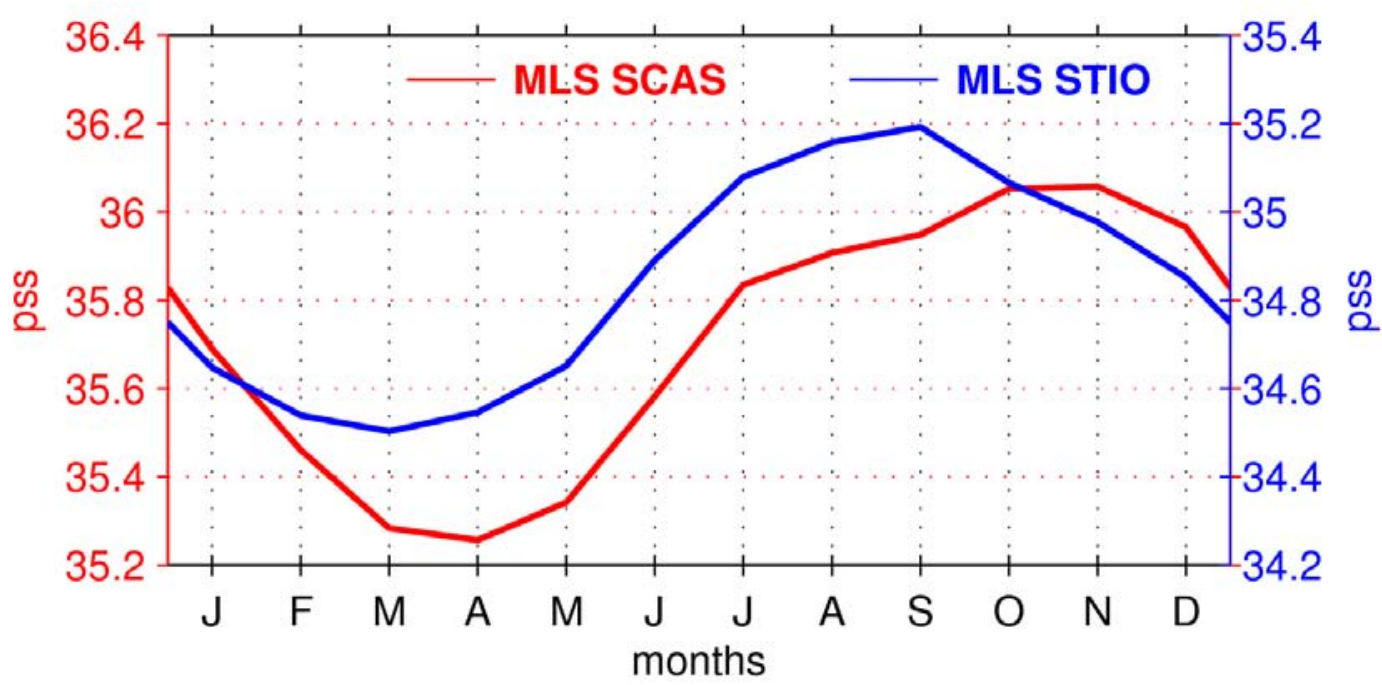

84

85

86

87

88

89

90

91

92

93

94 


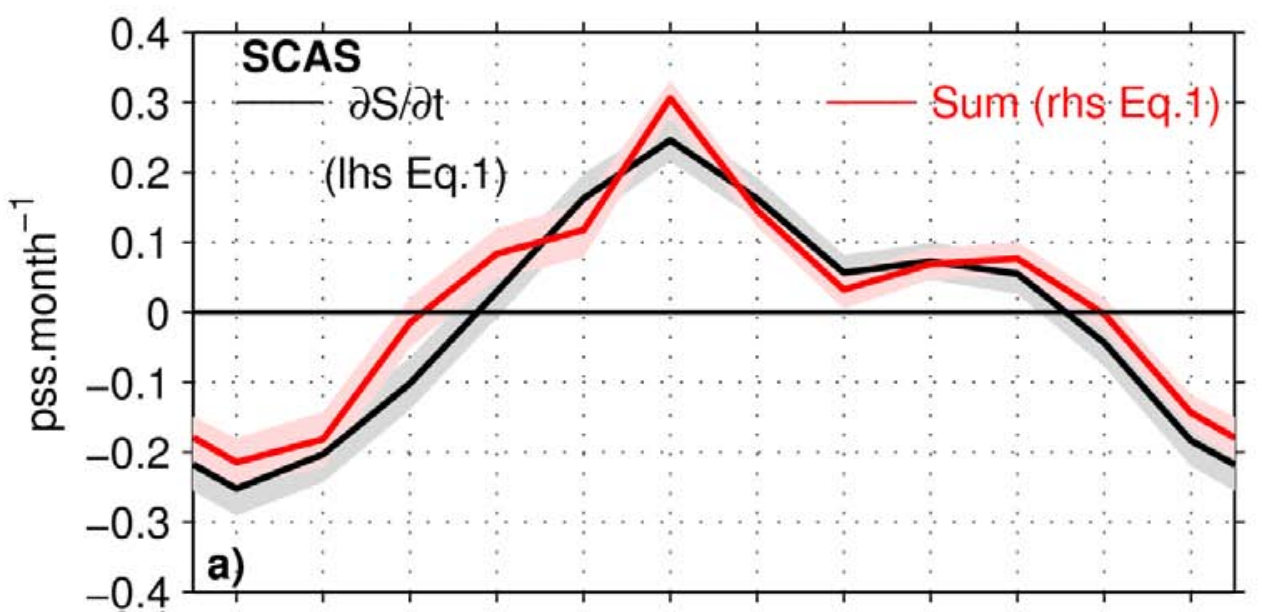

102

103

104

105

106

107

108

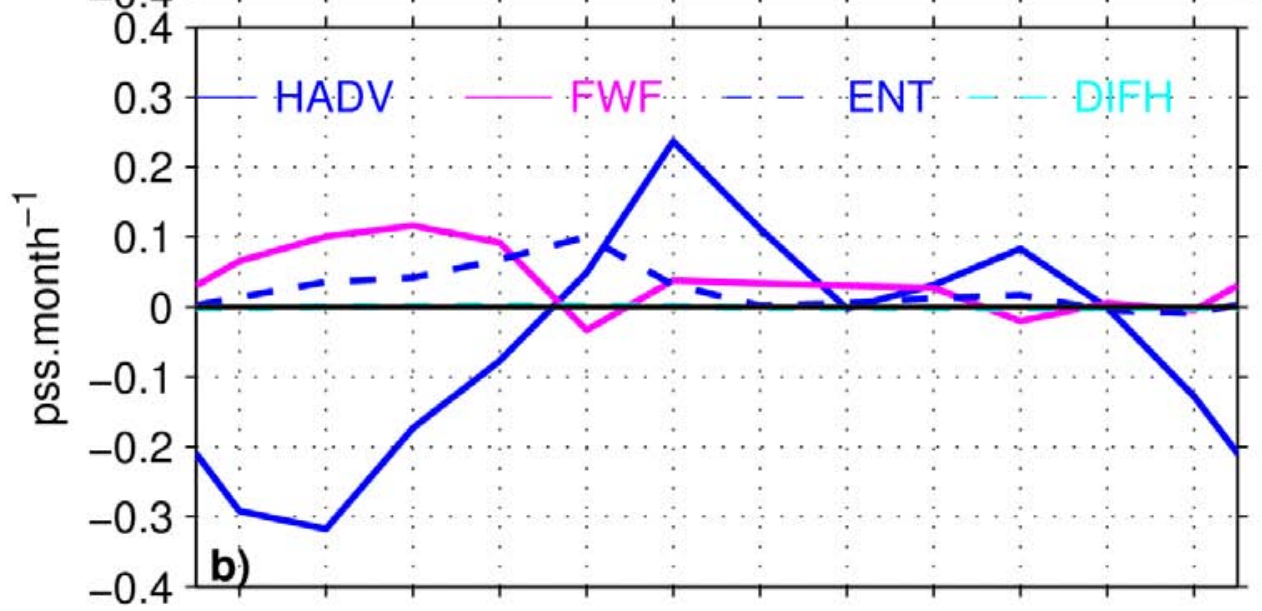

109

110

111

112

113

114

115

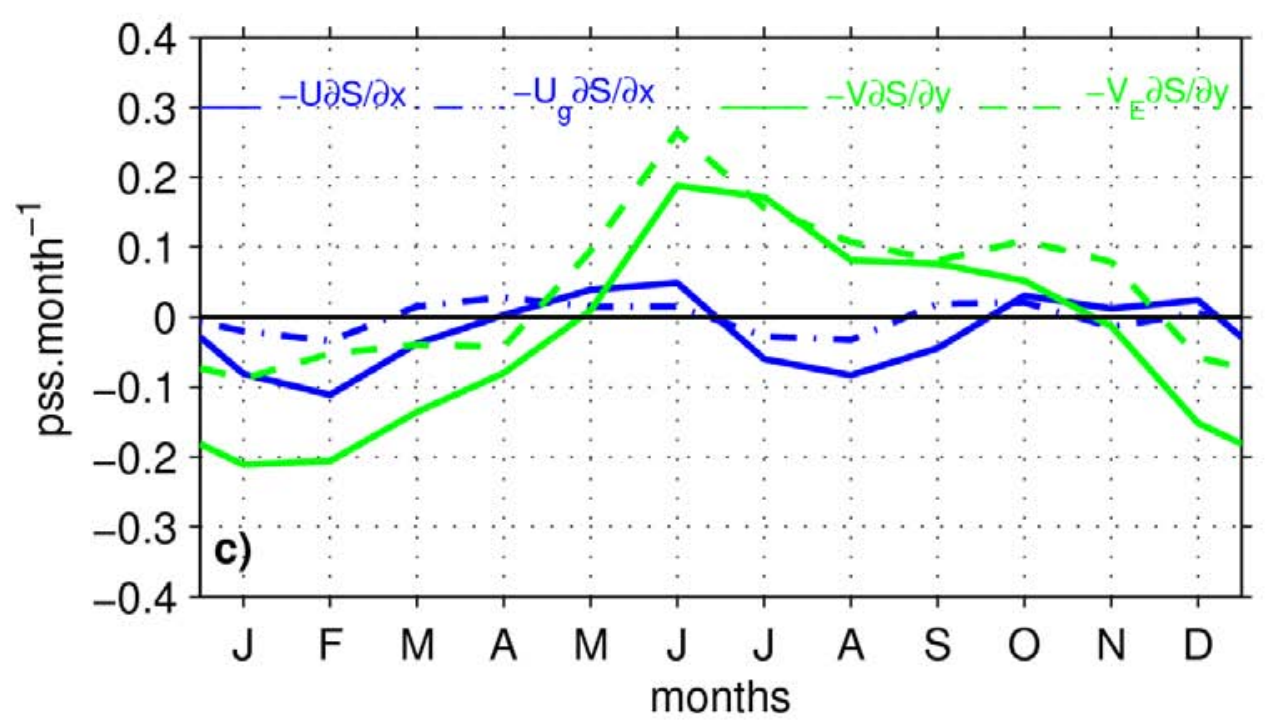

116

117 Figure 5. For the SCAS region: a) Observed and diagnosed MLS tendencies with the shaded

118 areas indicating error estimates (see Appendix) for these terms. b) Individual contributions to 
119 the salt budget equation for horizontal (zonal + meridional) advection (HADV in blue),

120 entrainment (ENT in dashed blue), freshwater flux (FWF in pink), and horizontal diffusion

121 (DIFH in light blue). c) Decomposition of the horizontal advection into Ekman (dashed green)

122 and geostrophic components (dashed blue).

123

124

125

126

127

128

129

130

131

132

133

134

135

136

137

138

139

140

141

142 

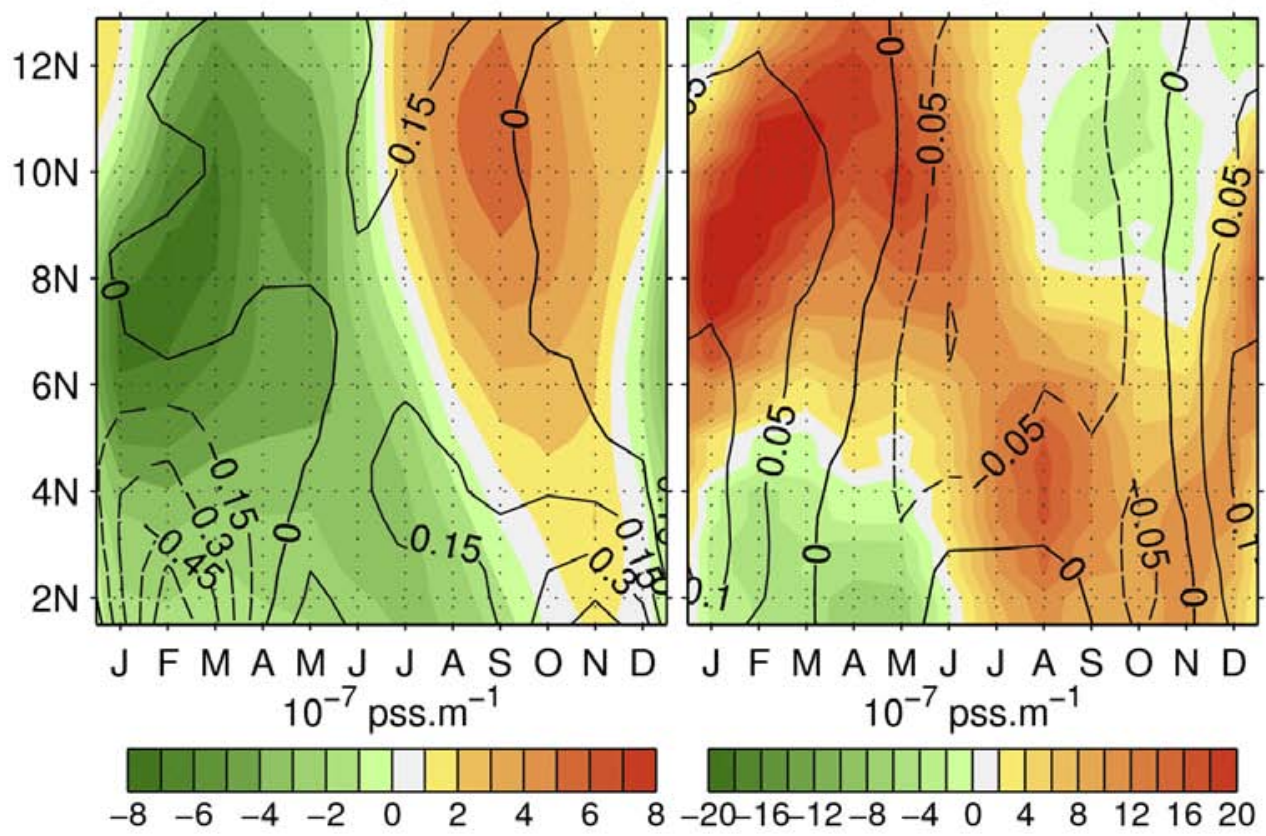

$10^{-7}$ pss.m $\mathrm{m}^{-1}$

$10^{-7}$ pss.m $\mathrm{m}^{-1}$

c) E-P

d) $S_{h}-S_{m}$ (shading) \& $W_{e}$ (contour)

154

155

156

157

158

159

160
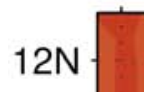

\section{$10 \mathrm{~N}$}

$8 \mathrm{~N}$

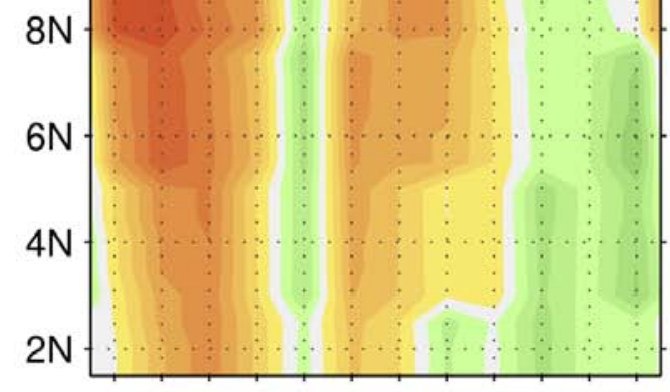

$J F M A M J J A S O N D$

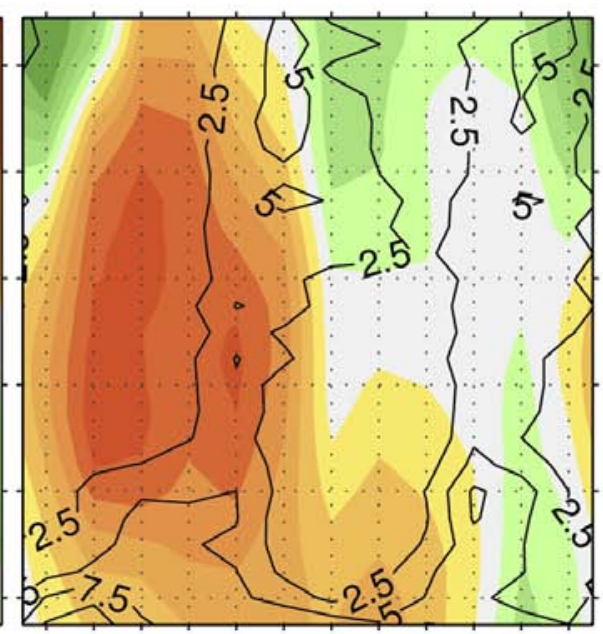

161

162

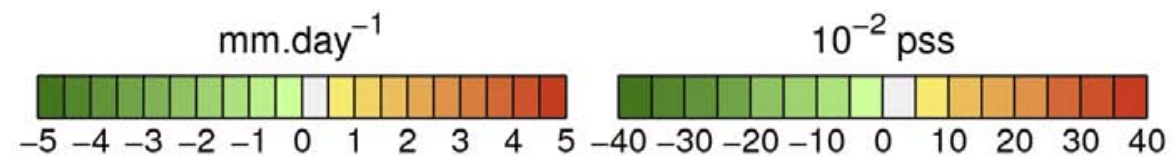

163

164 Figure 6. For the SCAS region: Latitude-time section for the SCAS region. a) Zonal MLS 
167 intervals are 0.05 m.s ${ }^{-1}$. c Difference between evaporation and precipitation (mm.day ${ }^{-1}$ ). d)

168 Salinity gradient near the mixed-layer base (pss) and the positive entrainment velocity in 169 contours $\left(10^{-6} \mathrm{~m} \cdot \mathrm{s}^{-1}\right)$. Contour intervals are $2.5 \mathrm{~m} \cdot \mathrm{s}^{-1}$.

170

171

172

173

174

175

176

177

178

179

180

181

182

183

184

185

186

187

188

189

190 


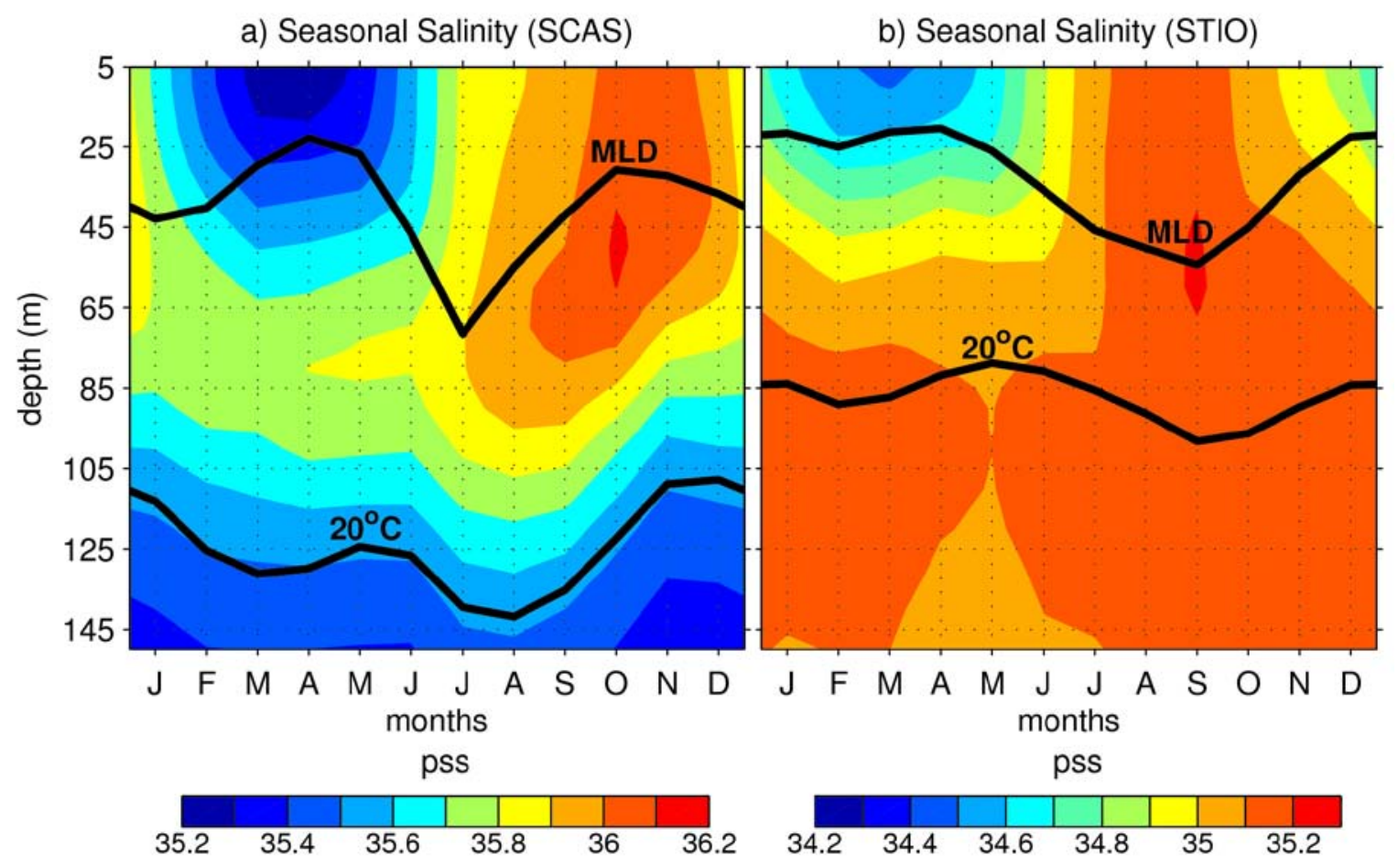

193

194 Figure 7. Vertical profile of the seasonal salinity averaged over the two focal areas a) SCAS

195 and b) STIO. Solid black lines show the mixed-layer depth (MLD) and the $20^{\circ} \mathrm{C}$ isotherm (a 196 proxy for central thermocline depth).

197

198 


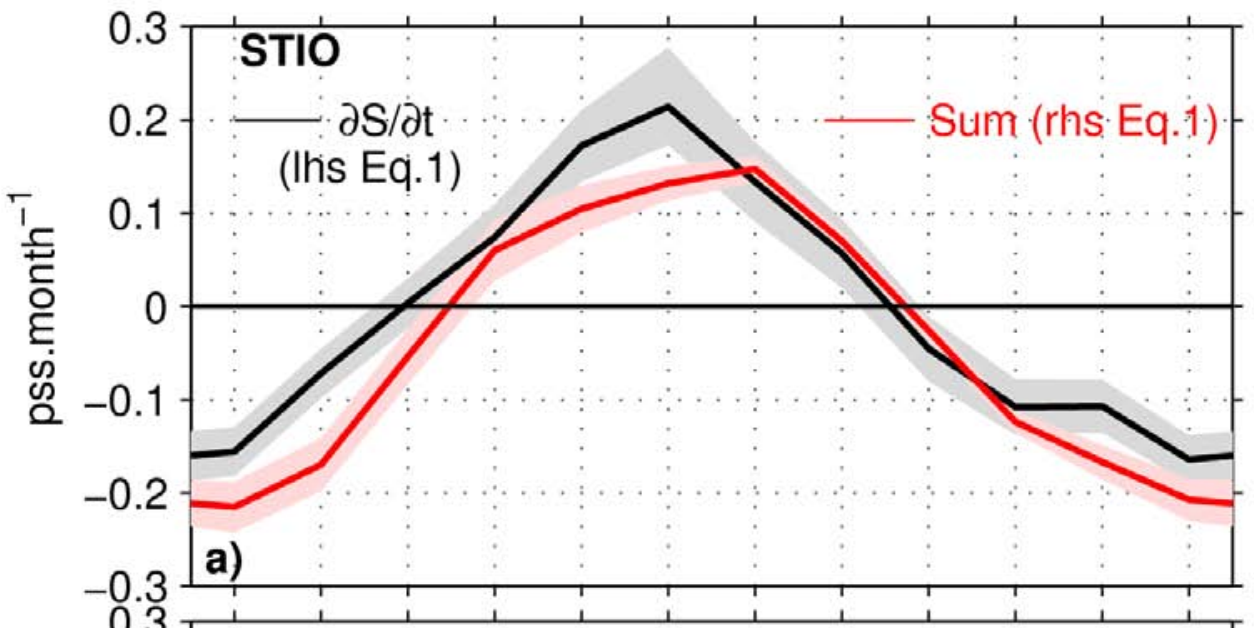

206

207

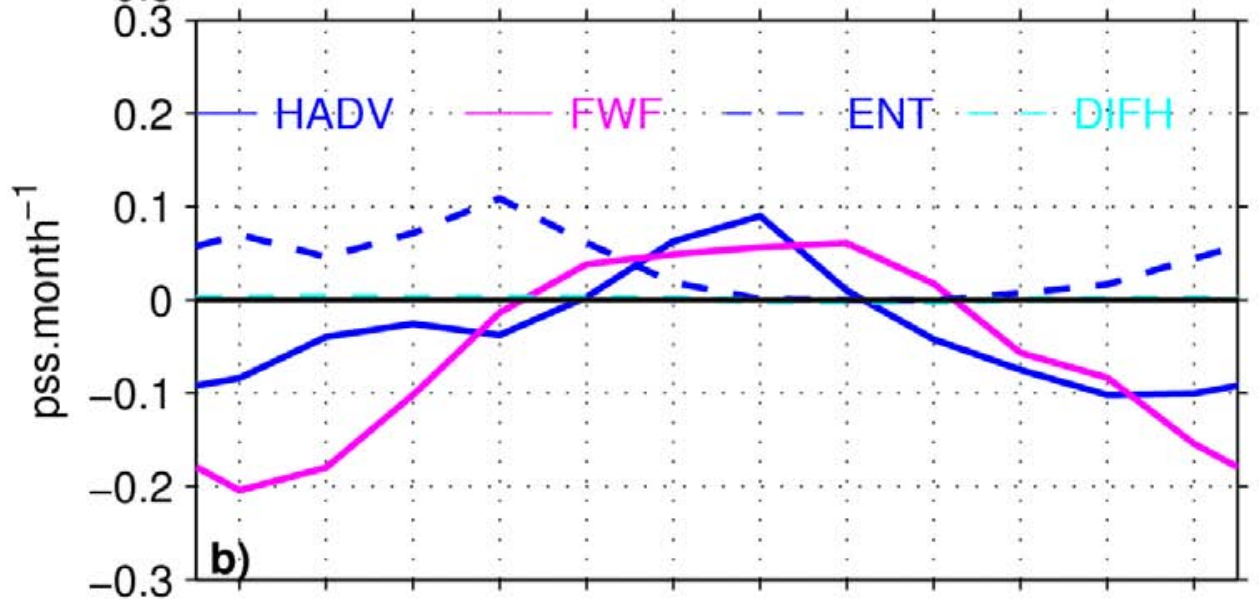

212

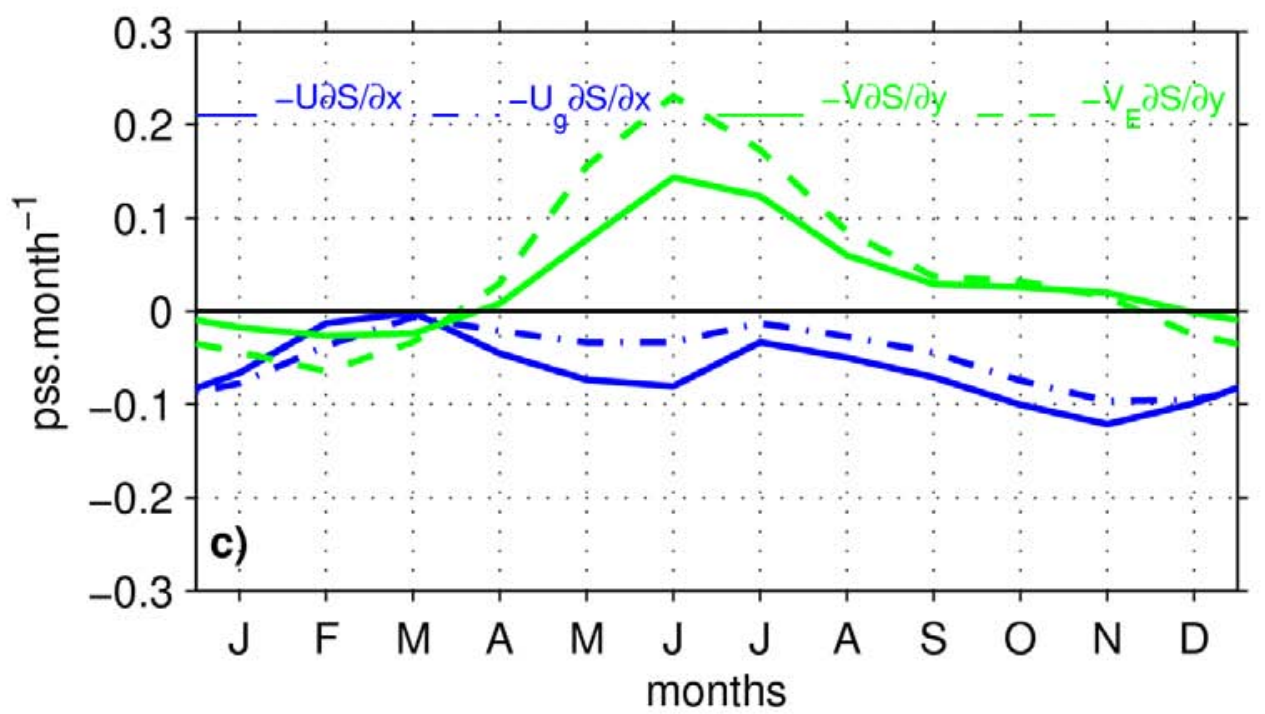

220

221

222 Figure 8. Same as Figure 5 except for the STIO region. 
a) $\partial S / \partial x$ (shading) \& $U$ (contour)

b) $\partial S / \partial y$ (shading) \& $V$ (contour)
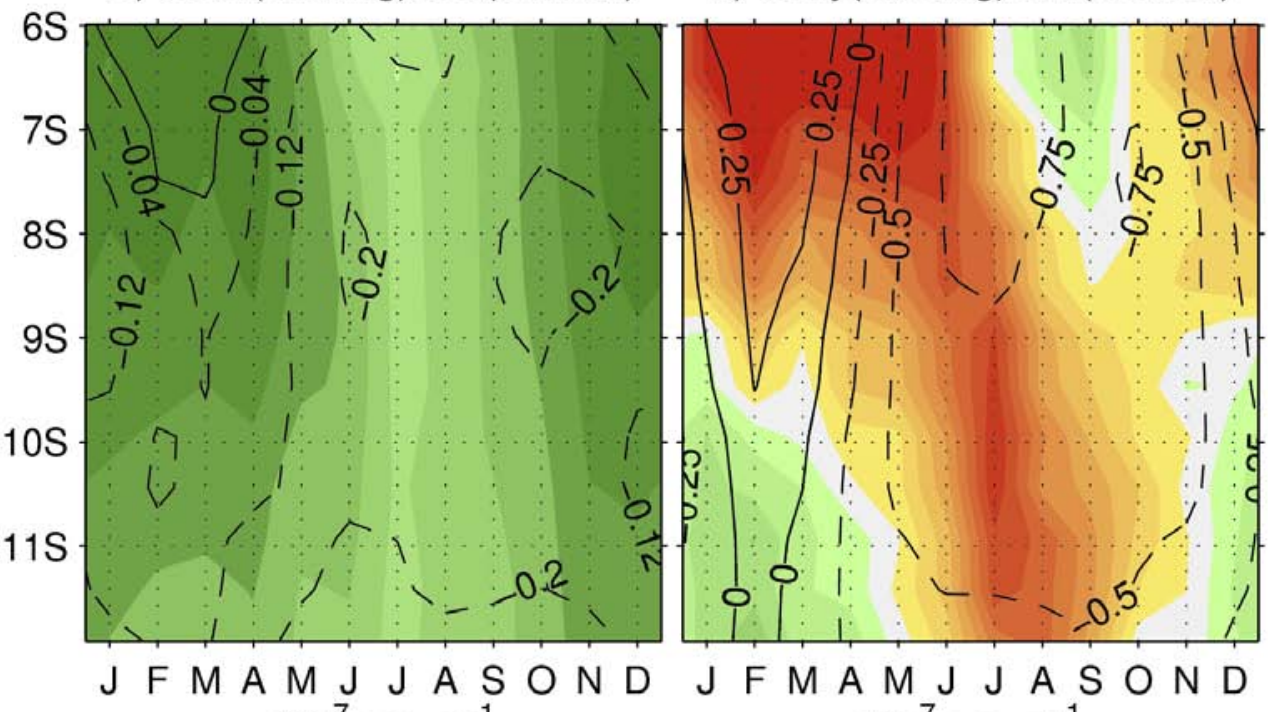

$10^{-7}$ pss. $^{-1}$

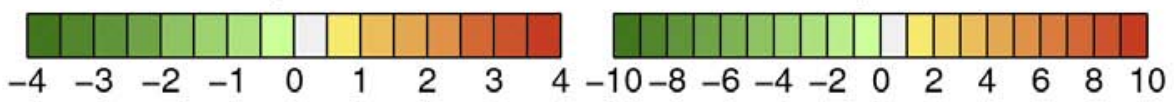

c) E-P

d) $S_{h}-S_{m}$ (shading) \& $W_{e}$ (contour)

234

235
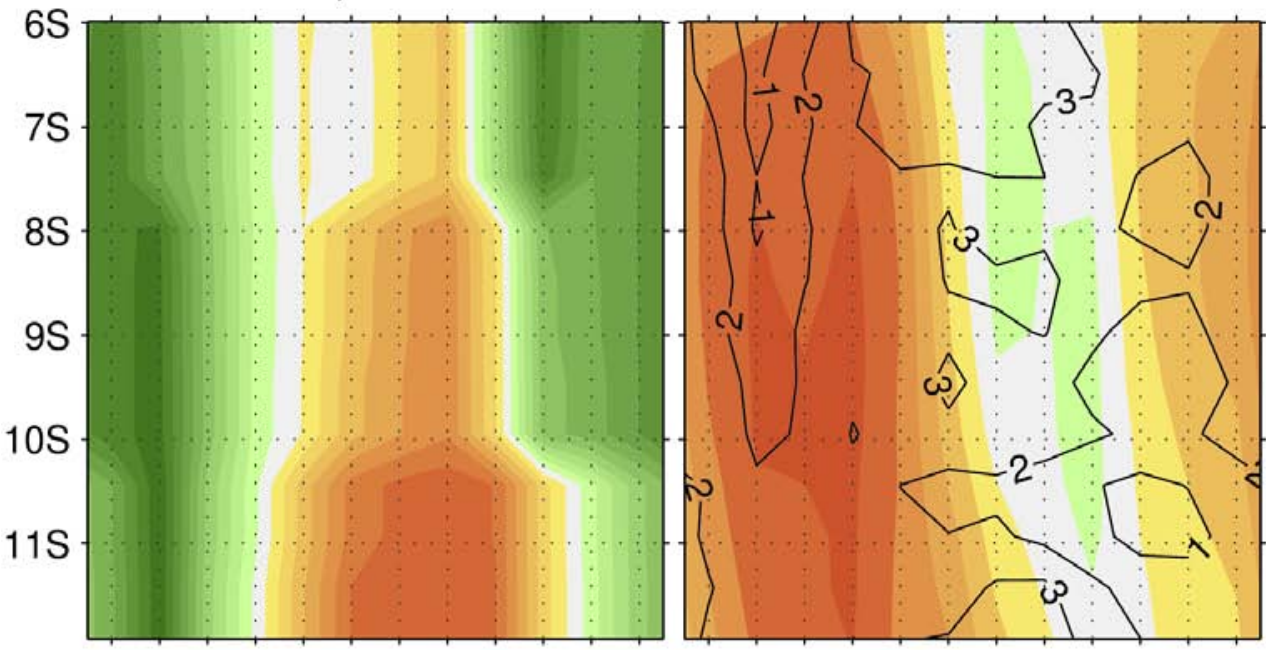

J F M A M J JASOND JFMAM J JASOND

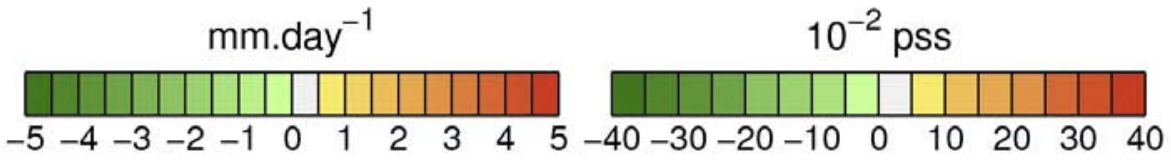

244 Figure 9. Same as Figure 6 except for the STIO region. Note that here contour intervals are

$0.08 \mathrm{~m} . \mathrm{s}^{-1}$ for a). Meridional current unit is $10^{-1} \mathrm{~m} . \mathrm{s}^{-1}$ and contour intervals are $0.25 \mathrm{~m} . \mathrm{s}^{-1}$ for

b). Contour intervals are $1 \mathrm{~m} \cdot \mathrm{s}^{-1}$ for $\mathrm{d}$ ). 


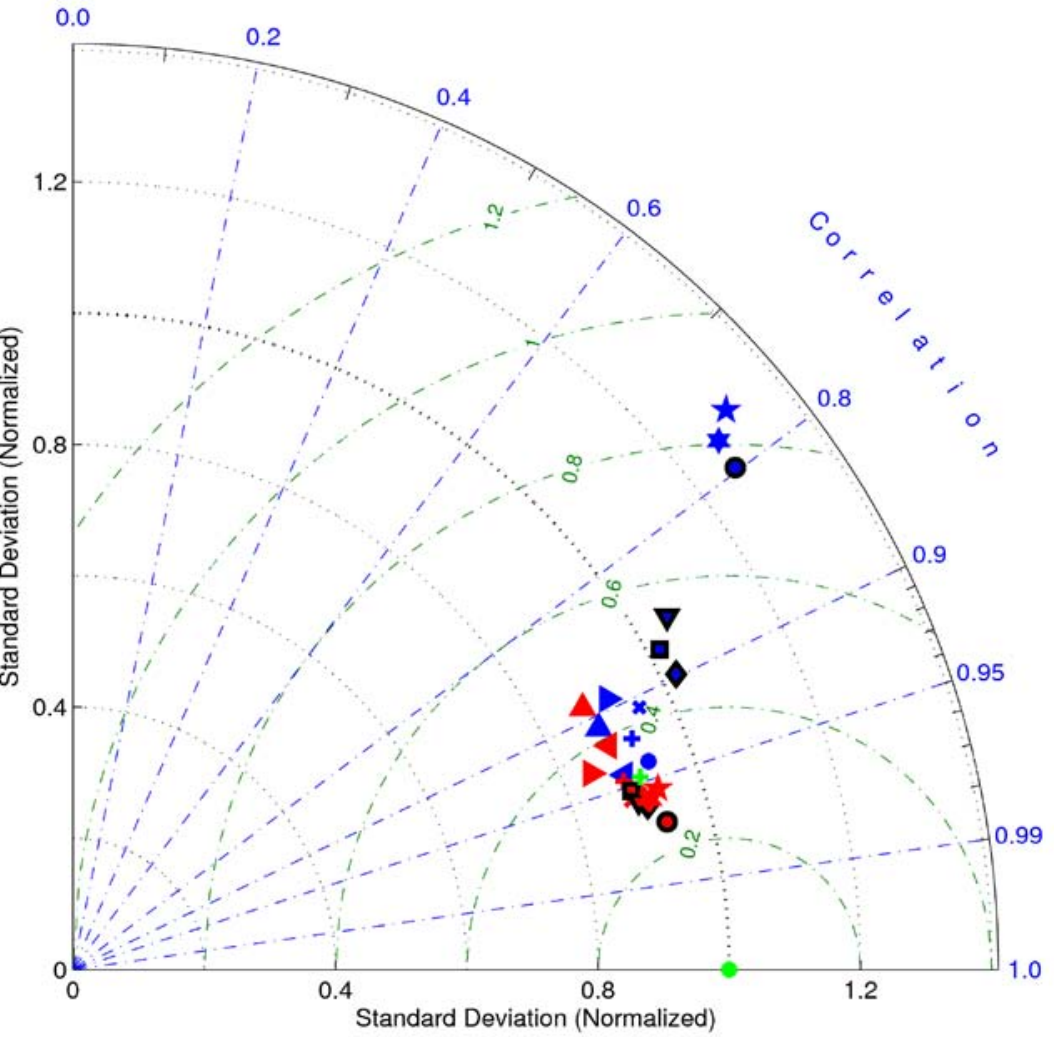

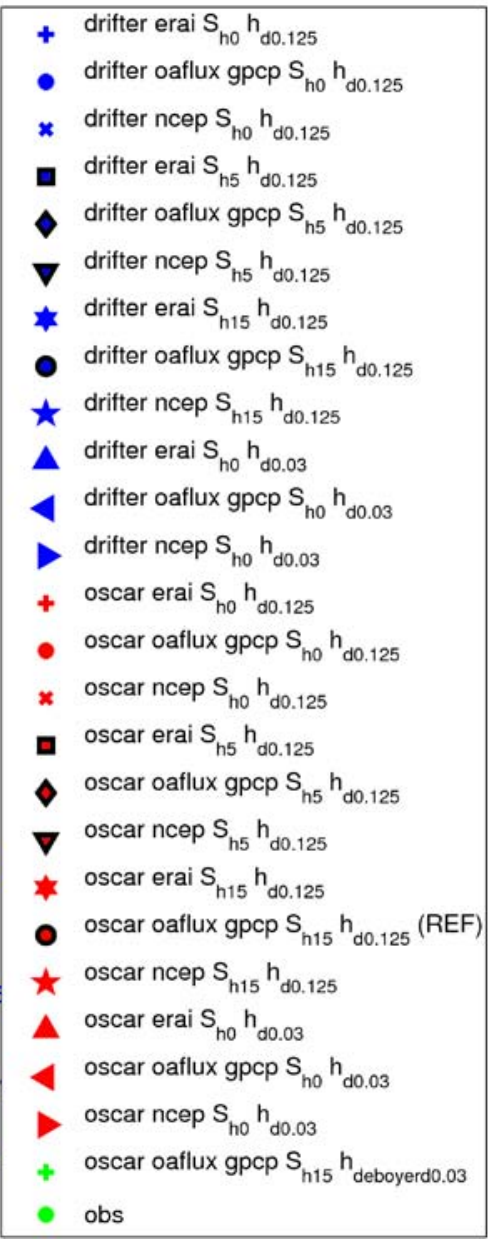

259
260
261
262
263
264
265
266
267
268
269
STIO region

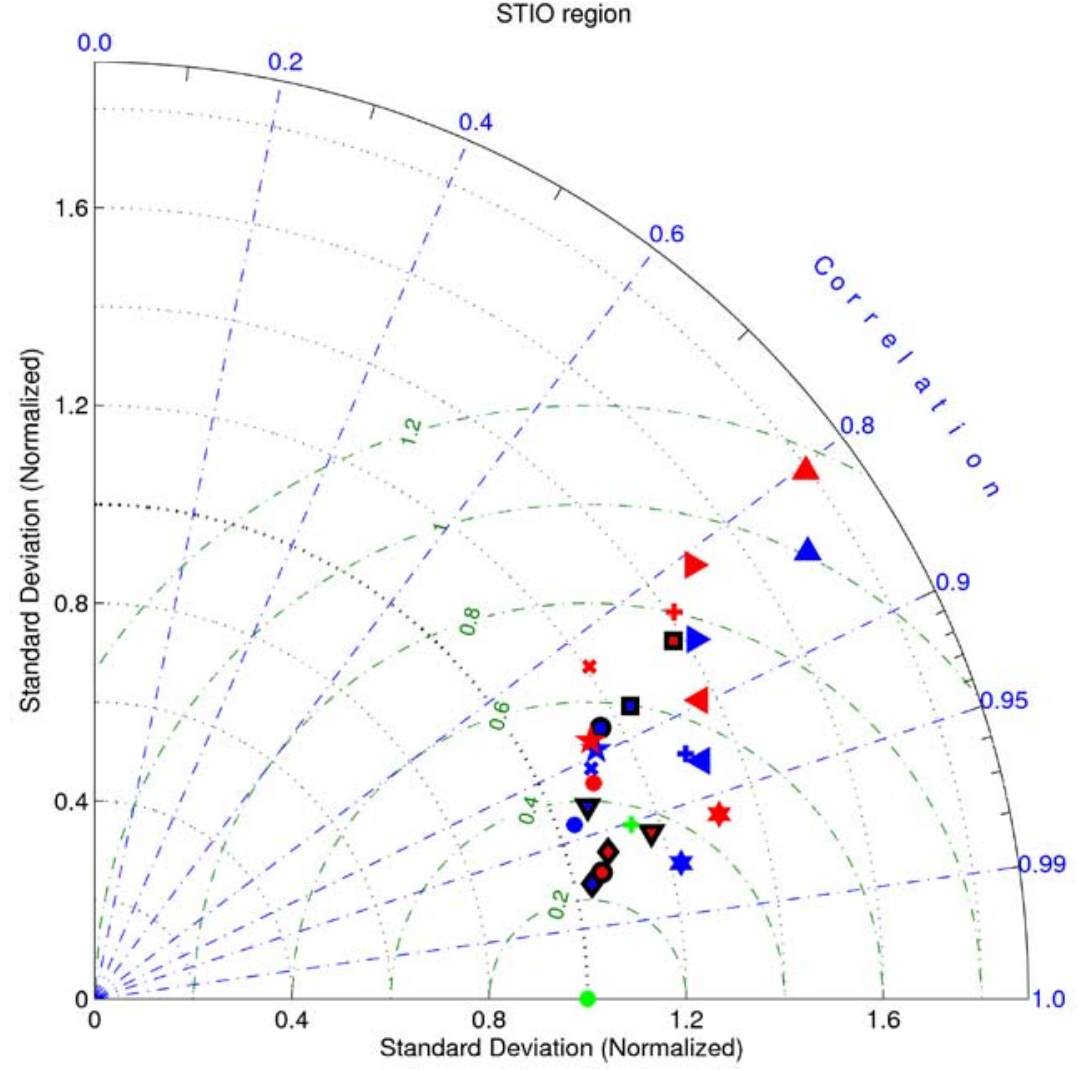


270 Figure A. Taylor diagram in the SCAS and the STIO regions. Observed and diagnosed MLS 271 tendencies are represented by points on a diagram where the correlation coefficient (R) 272 between the observed and diagnosed time series is given by the azimuthal position, standard 273 deviation of the observed or diagnosed time series is given by the radial distance from the 274 origin, and the centered root mean square difference (RMSD) is given by the distance 275 between the observed point and diagnosed point. REF is the reference experiment.

276

277

278

279

280

281

282

283

284

285

286

287

288 